\title{
Mutation in Breton verbs: pertinacity across generations ${ }^{1}$
}

\author{
HOLLY J. KENNARD \& ADITI LAHIRI
}

University of Oxford

\begin{abstract}
Although word-initial consonants are highly salient cross-linguistically, the process of initial consonant mutation has nonetheless continued to affect them in the Celtic languages. This paper investigates the use of the mixed mutation (MM) in Breton, following the progressive particle. Like all mutation it naturally affects the phonology, but also gives (redundant) information for morphosyntax. Mutation is generally presumed to be a regular process, but as there has been a gap in the transmission of Breton, the extent to which this phono-syntactic phenomenon is consistent across generations remains open to discussion. It has been claimed that younger speakers do not use mutation correctly, being strongly French-dominant. We tested this examining both distribution of usage, and acoustic measurements of the consonants in question. Data from original fieldwork indicate that young adults use MM in the same way as older speakers, but children attending Breton-medium schooling are less proficient. MM is difficult to acquire, the crucial factor being sustained Breton input beyond the early teenage years. Acoustically, there is no difference in the production of MM crossgenerationally. The difference between the two generations is in the use of the progressive particle itself, omitted by the older generation, but retained by younger speakers.
\end{abstract}




\section{INTRODUCTION}

Initial consonant mutation is a feature common to all the Modern Celtic languages, but is cross-linguistically unusual; it is rare among Indo-European languages, but it is found in other language families - for example Mende, spoken in Sierra Leone (Ball 1993: 189). It involves the replacement of word-initial consonant phonemes with other consonant phonemes, and this replacement is triggered by the morphological or syntactic context. For example, the initial consonant of the Breton word $t i$ 'house' undergoes mutation following certain possessive pronouns. 'My house' is therefore $m a$ $z i$, showing spirantisation, while 'his house' $e$ di, has lenition. Although mutation is thought to have originally been a phonetically-motivated process (Hannahs 2011), it is clear that the alternations above are triggered not by the phonological environment, but by the morphosyntactic context.

This paper examines one particular instance of mutation in Breton, namely the mixed mutation occurring on verbs following the progressive particle, and does so taking into account the current situation of the language. The Breton language has seen a vast decline in the number of speakers over the course of the twentieth century. While in 1946 there were thought to be around 1100000 speakers, a recent survey in 2007 estimated that only around 206000 speakers remained, of whom $46 \%$ were aged 75 or older (Broudic 2009). Transmission of the language from parent to child effectively ceased following the Second World War, following decades of political and social pressure. In more recent years, however, there has been renewed interest in the language, and language revival efforts have led to the establishment of Breton-medium schooling. Between 2002 and 2007, the number of children in Breton-medium education increased by $43.6 \%$ (Baxter 2009). However, Breton-medium education still 
accounts for a very small proportion of pupils in Brittany as a whole: in the 2013-2014 academic year, there were 15338 pupils in Breton-medium education (including the département Loire-Atlantique), which is only 1.74\% (Ofis Publik ar Brezhoneg 2014). The Breton taught in schools is sometimes termed Neo Breton, and is said to be different from the 'traditional' Breton of older speakers: it is a standardised form, which avoids French loanwords in favour of more 'Celtic' equivalents, but also shows influence from French in its morphosyntax and phonology - for example, the use of the uvular $[\mathrm{R}]^{2}$ in place of the apical [r] (Jones 1998), and the use of incorrect grammatical gender influenced by the gender in French (Hornsby 2005). These differences make Neo Breton appear unfamiliar or foreign to older native speakers, and as a result a gap has emerged between what are now two distinct generations of speakers. There are also cultural and educational differences between the two groups, which in turn contribute to discourage communication between them (German 2007). Thus, there is little 'corrective' influence from the older native speakers. With regard to mutation, it has been claimed that while mutation is productive for older speakers of 'traditional' Breton, in Neo Breton some or all of the mutation is lost or confused (Jones 1998: 302). In this paper, we examine the use of mutation in the context of this gap in transmission, focusing on the speech of two separate generations. Research into word order has shown that separate generations of speakers differ relatively little in terms of their syntax (e.g. Kennard 2014). Mutation, however, is on the interface between phonology and morphosyntax, and might be more vulnerable to change: do we find a difference between the generations here? A number of possibilities emerge: it could be that the younger generation are not able to use mutation in the same way that the older generation do, because they are not learning the language from their own parents. They 
have limited input in terms of both the amount of exposure, and the contexts in which the language is used; indeed, most children have no exposure to native Breton. Equally, it may be that the mutation in question is not being perceived by the younger generation, that the phonemes in question are in some way ambiguous in this context.

The paper is organised as follows: Section 2 presents an overview of mutation in Breton; in Section 3 the fieldwork methodology is discussed; Section 4 then examines the use of the progressive particle in the two generations of speakers, while in Section 5 the use of mutation across the two generations is examined. In Section 6 we investigate the acoustic properties of the consonants involved in the mixed mutation, and the findings from the fieldwork and their indications are discussed as a whole in Section 7 , and we conclude that despite the markedness of mutation and difficulties in transmission, mutation, though variable, continues to be used persistently across generations.

\section{MUtATION IN BRETON}

It is important to note that the changes caused by initial-consonant mutation, as opposed to regular phonetic or phonological alternations, involve only phonemes of the language. For example, Breton feminine singular nouns undergo a mutation (specifically, lenition) following the article. The noun merc' $h$ 'girl' becomes $\operatorname{ar}$ verc' $h$ 'the girl', with both $/ \mathrm{m} /$ and $/ \mathrm{v} /$ being phonemes in Breton. This means that mutation can in fact be considered a type of neutralisation: the contrast between two phonemes is being lost. In the written language, this can lead to ambiguity, since if a word appears in a mutation context, there is no way to determine from that one instance whether the consonant is a mutated form or not. For example, in the phrase ar bal, the initial $b$ might be a mutated form (from $p$ ), or a non-mutated, radical form. The words pal and bal both 
exist in Breton: the first is a spade, and the second a ball, in the sense of a dance. Since pal is a feminine noun, the initial consonant is lenited after the definite article; however, bal is a masculine noun, and so is not subject to this mutation rule. Both therefore surface as ar bal. In the spoken language, there is less likely to be confusion: some dialects have a long vowel in 'spade' [ав ba:1], but not in 'ball' [ав bal], and the exact phonetic realisation of the consonant may differ. The latter issue will be discussed further in Section 6.

There are generally considered to be four classes of mutation in Breton: lenition, also known as the soft mutation; spirantisation, or the spirant mutation; provection; and the mixed mutation, so called because it incorporates parts of lenition and parts of provection, and is therefore referred to by some writers as leniprovection. Table 1 presents an overview of mutation in Standard Breton from the point of view of the phonemes themselves, indicating how these are affected by the different types of mutation, and in what contexts these changes apply. It should, of course, be borne in mind that the dialects vary in their exact realisation of these phonemes; this table is intended as a reference for the discussion of data to follow. Our particular interest in this paper is the mixed mutation, shaded in grey in Table 1. 


\begin{tabular}{|c|c|c|}
\hline \multicolumn{3}{|c|}{ VOICELESS STOPS } \\
\hline$/ \mathbf{p}, \mathbf{t}, \mathbf{k} /$ & Mutated form & Context \\
\hline$[\mathrm{b}, \mathrm{d}, \mathrm{g}]$ & Voiced stops & Lenition \\
\hline$[\mathrm{f}, \mathrm{z}, \mathrm{x}]$ & Fricatives & Spirantisation \\
\hline \multicolumn{3}{|c|}{ VOICED STOPS } \\
\hline$/ \mathbf{b}, \mathbf{d}, \mathbf{g} /$ & Mutated form & Context \\
\hline$[\mathrm{v}, \mathrm{z}, \mathrm{h}]$ & Fricatives & Lenition \\
\hline$[\mathrm{p}, \mathrm{t}, \mathrm{k}]$ & Voiceless stops & Provection \\
\hline$[\mathrm{v}, \mathrm{t}, \mathrm{h}]$ & $\begin{array}{l}\text { Fricatives } \\
\text { Voiceless stop }\end{array}$ & Mixed mutation \\
\hline \multicolumn{3}{|c|}{ NASAL BILABIAL STOP } \\
\hline$/ \mathbf{m} /$ & Mutated form & Context \\
\hline$[\mathrm{v}]$ & Non-nasal fricative & $\begin{array}{l}\text { Lenition } \\
\text { Mixed mutation }\end{array}$ \\
\hline \multicolumn{3}{|c|}{ CONSONANT CLUSTER } \\
\hline /gw/ & Mutated form & Context \\
\hline [w] & Loss of initial consonant & $\begin{array}{l}\text { Lenition } \\
\text { Mixed mutation }\end{array}$ \\
\hline$[\mathrm{kw}]$ & Devoicing of initial consonant & Provection \\
\hline
\end{tabular}

Table 1

Phonological summary of mutation in Standard Breton

As Table 1 shows, in some cases the same transformation of a phoneme occurs in more than one type of mutation: for example, $/ \mathrm{b} /$ changes to $/ \mathrm{v} /$ in both lenition and the mixed mutation. Since this paper is concerned in particular with the mixed mutation, itself a combination of lenition and provection, the following discussion examines the particular contexts in which these mutations are found. Spirantisation is not relevant to this discussion, and will not be considered further.

Lenition transforms the voiceless stops /p, t, k/ into the voiced stops /b, d, g/, the voiced stops $/ \mathrm{b}, \mathrm{d}, \mathrm{g} /$ into the fricatives $/ \mathrm{v}, \mathrm{z}, \mathrm{h} /{ }^{\beta}$, the nasal $/ \mathrm{m} /$ into the fricative $/ \mathrm{v} /$, and the cluster/gw/ into /w/. Like in Welsh, lenition is the most common form of mutation in Breton. It affects the greatest number of initial consonants (or consonant clusters), and is the most wide-reaching mutation, being triggered in the greatest number of morphosyntactic contexts. To give a brief survey, we find lenition on nouns, for example, following the possessives $d a$ 'your (SG)' and $e$ 'his', and a number of 
prepositions. Feminine singular nouns undergo lenition following the definite article. Attributive adjectives also undergo lenition if the noun they modify is itself lenited. A number of preverbal particles trigger lenition on a following verb, as will be discussed further in Section 4.4

In a sense, provection is usually the reverse of lenition, since it transforms the voiced stops $/ \mathrm{b}, \mathrm{d}, \mathrm{g} /$ into their voiceless counterparts $/ \mathrm{p}, \mathrm{t}, \mathrm{k} /$; however, in the standard language at least, it affects far fewer consonants. ${ }^{5}$ It is the most restricted of the Breton mutations in terms of applicable contexts, being found only on nouns following certain little-used direct object pronouns, and after the second person plural possessive ho.
(1) breur $\rightarrow$ ho preur
brother $\rightarrow$ your.PL brother

It is interesting to note, as does Press (1986), that although Breton mutation has a general tendency towards increasing sonority, provection is an exception, and in fact decreases sonority, being the only type of mutation to do so.

In the standard language, the mixed mutation affects only the voiced stops $/ \mathrm{b}, \mathrm{d}, \mathrm{g} /$, the nasal $/ \mathrm{m} /$, and the cluster $/ \mathrm{gw} /$ : although it closely resembles lenition, it is less wideranging in terms of the phonemes it involves (e.g. Press 1986; Ternes 1992). The stops /b/, /g/ and /m/ undergo lenition, and are transformed into fricatives as described above. The cluster /gw/ is also lenited, losing the initial stop and becoming /w/. However, the alveolar voiced stop /d/ undergoes provection, and is devoiced to /t/.

The mixed mutation is found only on verbs and is triggered by the verbal particles $e$ (used when an element other than the subject, object or verbal noun precedes the verb) and $o$ (the progressive marker); and, in some dialects, the conjunction $m a$ 'if' ${ }^{6}$ 
(2) gwiskañ $\rightarrow$ alies e wisk un tog wear.VN $\rightarrow$ often PRT wear.3SG DET hat 'She often wears a hat.'

(3) dañsal $\rightarrow$ emañ $\quad$ o tañsal dance.vN $\rightarrow$ be.SIT.3SG PRT dance.PROG

'He is dancing.'

(4) dont $\rightarrow$ laouen e ve-fen ma teu-fe come.VN $\rightarrow$ happy PRT be-COND.1SG if come-COND.3SG 'I would be happy if he came.'

It is the mutation following the progressive particle, as in (3), that is of interest in this study. There are two important points to mention in relation to this. The first is that the realisation of the progressive particle varies across dialects. While the standard language has $o$ (or $o c^{\prime} h$ before a vowel), many dialects have [e] or [i], and a look at the Atlas Linguistique de la Basse Bretagne (map 474) indicates that, where it is used, $o$ is actually in a minority across Lower Brittany (10 of 81 locations) (Le Roux 1924-1963). The second is that in some (mainly northern) dialects there may be less ambiguous evidence for the mixed mutation, since it is not identical to lenition in consonants such as $/ \mathrm{b} /$ and $/ \mathrm{m} /$, and may result in $/ \mathrm{f} /$, not $/ \mathrm{v} /$ (Favereau 1997). Jackson (1967) writes that this arises from the nature of the mixed mutation itself, which he terms an 'analogical disturbance' of the mutation 'lenition-and-provection' (Jackson 1967: 333). At an earlier stage of the language, certain contexts provoked lenition of a following initial consonant, but later sound changes meant that provection was then triggered in addition. In some dialects this entire process (e.g. $/ \mathrm{b} />/ \mathrm{v} />/ \mathrm{f} /$ ) was maintained, but in the majority, only initial/d/ preserved the provection part of the process, while the other 
consonants remained at the lenition stage. The dialect under consideration in this study largely uses the mixed mutation as it has been described for the standard language; any variations from this will be discussed as they occur.

Before looking at the data, it is worth considering the possible alternatives that might be found. Logically, there are three possibilities. First, speakers might do as expected, and use the appropriate mutation for the context. Secondly, speakers might use some sort of mutation, but not the expected mutation for the context. Thirdly, they might use no mutation at all, leaving the verb in its unmutated form.

The mixed mutation, by its very nature, resembles both lenition and provection: four of the five segments affected by the mixed mutation are changed in exactly the same way a they are changed by lenition; only /d/ is changed as in provection (a mutation we would not expect see on a verb, as discussed above). It would therefore not be surprising to find that speakers were using lenition in place of the mixed mutation. The biggest complication when considering the mixed mutation is that for $/ \mathrm{b}, \mathrm{g}, \mathrm{m}, \mathrm{gw} /$ there is likely to be no means of discovering whether speakers are indeed using the mixed mutation, or if they are using lenition: the results will probably be the same. The only consonant where this distinction can be made is $/ \mathrm{d} /$.

The data to be discussed thus recognise four different categories of mutation use: mixed mutation, ambiguous lenition, incorrect lenition and no mutation. Mixed mutation applies only to /d/-initial verbs, where the distinction between lenition and the mixed mutation is clear, and signifies the change from $/ \mathrm{d} /$ to $/ \mathrm{t} /$. Ambiguous lenition is therefore applied to the mutations $/ \mathrm{b} />/ \mathrm{v} /, / \mathrm{g} />/ \mathrm{h} /, / \mathrm{m} />/ \mathrm{v} /$ and $/ \mathrm{gw} />/ \mathrm{w} /:$ these could be the mixed mutation, but they could also be lenition. Incorrect lenition refers to the mutation $/ \mathrm{d} />/ \mathrm{z} /$ : this is unquestionably lenition, and cannot be the mixed mutation. 
Theoretically, this category could also encompass the lenition of the voiceless stops /p, $\mathrm{t}, \mathrm{k} /$, since these are affected by lenition but not the mixed mutation. However, there are so few instances of this occurring in the data (four in total, across all speakers), that they will not be considered, and this is not included in the definition of this category. Finally, no mutation is self-explanatory: no mutation has taken place at all. These four categories are illustrated in examples (5-8).

(5) Mixed mutation: $d>t$

emañ ar paotr o tebriñ $[<$ debriñ $]$ be.SIT.3SG DET boy PRT eat.PROG

'The boy is eating.'

(6) Ambiguous lenition: $b>v, g>h, m>v, g w>g$

emañ ar plac'ho vousc'hoarzhin $[<$ mousc'hoarzhin $]$

be.SIT.3SG DET girl PRT smile.PROG

'The girl is smiling.'

(7) Incorrect lenition: $d>z$

*emañ ar paotr o zebriñ $[<$ debriñ $]$

be.SIT.3SG DET boy PRT eat.PROG

'The boy is eating.'

(8) No mutation

*emañ ar paotr o debriñ

*emañ ar plac'h o mousc'hoarzhin

These are then the categories of data that will be used in the discussion to follow. 


\section{FIELDWORK METHODOLOGY}

The data used in this study were collected over the course of two fieldwork visits to Brittany, the first in March 2010, and the second in October 2011. The participants interviewed came from the area within and around Quimper, which is a moderately large town in the southwest of Brittany, and the administrative centre of the most westerly Breton département, Finistère. This part of Brittany falls within the Kerneveg dialect region, and the Breton of rural areas to the north and west of Quimper have not been widely studied. There are some descriptions of varieties of Kerneveg such as that spoken in Douarnenez (Denis 1977), or the Bigouden region (e.g. Dressler \& Hufgard 1980), but much research has focused more on Leoneg and Tregerieg, as Bothorel (1982) notes, and on differences between Gwenedeg and the other dialects (e.g. Costaouec 1998; 2010). Kerneveg may have a wider range of mutation than has been found in some other areas: it is well-documented (e.g. Stephens 1993) that Tregerieg and some parts of central Brittany have lost lenition of /d/, for example, but this is not the case for the western part of the dialect area of Kerneveg.

As explained above, one of the goals of this study is to investigate any potential differences in mutation usage between two generations separated by a gap in transmission. Speakers of different ages were therefore chosen to take part. First, an older generation of SENIOR ADULTS, and secondly two groups of speakers from the younger generation, all of whom could be described as Neo-Breton speakers: YouNG ADULTS, who have formerly received some Breton education and who are now working in situations requiring the use of Breton on a daily basis; and CHILDREN who are currently in Breton-medium education. Thus, the senior adults acquired Breton in a normal fashion as in other linguistic communities and were monolingual before they 
went to school when they had to learn French. The other two groups learnt rather than acquired Breton, and French is a dominant language in their lives. Thus, the Breton of these three communities may well differ and our goal is to investigate the precise differences.

\subsection{Senior adults}

Five older speakers (J, N, K, QN and X) were interviewed for the fieldwork, all of whom were aged 65 or older, and who grew up speaking Breton at home, with their parents and extended families. Several of them spoke no French at all before they started school, aged about six, at which point they were required to speak French. The decline in the Breton language has left the remaining speakers in rural areas, rather than in towns (as discussed above), and the speakers in this study have lived all their lives in small villages in the area surrounding Quimper. They now speak Breton with close family and friends, and they all have a Breton-speaking spouse.

The senior adults' use of mutation acts as the baseline for the variety of the Breton spoken in the area (although it should be noted that most teachers in Breton-medium schools are not local to the region in which they teach), given that the senior adults could be considered to have acquired the language 'normally'. It must be kept in mind, however, that they were also under pressure not to speak Breton when they were young, particularly at school, and that a number of them did not pass the language on to their children.

\subsection{Young adults}

The second group of participants in the fieldwork are young adults (nine in total took part in the study: C, D, E, H, I, L O, TX and VY). They attended Breton-medium schooling, but their parents were not fluent Breton speakers. Aged between 20 and 35, 
they all underwent schooling or classes in Breton when initiatives in Breton-medium education such as Diwan (lit. 'sprout') were becoming quite well-established. They learnt Breton in a variety of ways: for example, speaker E was a pupil at a bilingual Divyezh school, (like a number of the children who took part in this study), while speaker I (the oldest of the young adult speakers) heard Breton spoken by older relatives while he was growing up, but only began to speak it himself when he learnt it at school.

These speakers use Breton on a day-to-day basis, since they all have occupations directly related to the use of the language. Telephone conversations, interaction with the public and in some cases office chat all take place in Breton, but of course they are all also native French speakers.

\subsection{Children}

The ten children participating in this study are part of the same linguistic generation as the young adults; that is, they are currently attending Breton-medium schooling, but their parents are not Breton-speakers themselves, and the language of the home is therefore French. Aged from eight to fifteen at the time of the fieldwork visits, they attend two types of Breton-medium education. Three, A, B and T, attend a Diwan school, which is privately run. The schools teach by immersion: the children begin by learning exclusively in Breton from as early as age 2, and come to read and write French at a later stage. The schools are independent of the state, but receive some state funding. As they were interviewed outside school hours, it was possible to visit these children on both fieldwork visits. They were aged 8,13 and 14 at the time of the first visit, and 10, 15 and 15 at the time of the second, respectively.

The other children attend Divyezh 'two languages' schooling, the state-run bilingual stream, which uses a bilingual teaching method (the classes are referred to as classes 
bilingues) whereby the children learn in Breton from an early age (children can attend an école maternelle from age 2), but learn to read and write in French before they do the same in Breton. The children in this study who attend Divyezh classes (AJ, BK, CG, EL, FM, F and Y) do so in the context of 'normal' French primary schools, as is often the case: alongside the classes bilingues are French-only classes of the same age-groups, and the children mix at break- and lunch-times. They were all in their final year of primary school (école élémentaire) and so aged 10 or 11 at the time of interview.

\subsection{Elicitation}

Participants were interviewed either individually or in groups of two. Their speech was recorded, and written consent had been given in accordance with the ethical approval the study had obtained. For the children, written parental consent was obtained. Two methods were used to elicit the data. In the first of these, participants were shown a series of photographs and short films (up to 10 seconds) with people or animals performing actions, and were asked to tell the interviewer, in Breton, what was happening in the picture or the film. For example, a photograph of three children eating cakes was shown, for which the intended response was an approximation of 'the children are eating cakes' (debriñ 'to eat' > o tebriñ 'eating'). Progressive utterances, which require the use of the progressive particle $o$, were easily elicited in this way, since it is natural to use the progressive to describe what is happening. The actions portrayed in the photographs were carefully chosen to elicit verbs that are susceptible to mutation, and, for the most part, this was successful. One advantage of using pictures as prompts for the elicitation of utterances is that they do not require translation from French, which might lead to interference between the two languages, and skewed results. Naturally, however, this technique allowed less control over the speakers' choice of words than 
translation would have done, and at times speakers did not use the carefully-selected verbs that had been intended.

\section{USE OF THE PROGRESSIVE PARTICLE}

This paper is concerned with the use of mutation following the progressive particle, and so the starting point for the discussion of the data in fact centres on the particle itself. Preverbal particles are common to all the Celtic languages, and there are four main particles in Breton. Two are found in normal main clause utterances, and their use is determined by the nature of the initial constituent: $a$ is used following the subject, object or verbal noun, while $e$ is used following any other initial constituent. These particles both provoke mutation on the verb ( $a$ provokes lenition, while $e$ provokes the mixed mutation), but have no particular meaning, simply agreeing with the initial constituent. There is also a preverbal negative particle $n e$, which replaces $a$ or $e$, and which is used in addition to a postverbal negative marker, ket. Ne also provokes lenition on the verb. Finally, the progressive particle $o$ (or $o c^{\prime} h$ before a vowel) precedes the verbal noun, and together with an auxiliary, the situational form of the verb bezañ 'to be', conveys progressive aspect. As already discussed, it provokes the mixed mutation. There are a number of reports in the literature (e.g. Dressler 1991) of the fact that native Breton speakers frequently omit preverbal particles in speech, but that when they do so, the mutation that the particle would trigger is maintained. Thus, utterances such as (9) are found:

(9) Absent particle

$$
\begin{aligned}
& \text { ar paotr [a] wel ur c'hi } \\
& \text { DET boy [PRT] }
\end{aligned}
$$

'The boy sees a dog.' 
Despite the fact that the particle is missing, the verb still shows lenition from the verbal noun gwelet to the third person singular form wel. The same is true of the progressive particle: it can be omitted in speech, but if so the verb still undergoes the mixed mutation. This section examines how frequently the three groups of speakers use the progressive particle, to see to what extent they omit it in speech, and whether there are differences in particle usage between the different generations.

As mentioned above, the preverbal particles $a$ and $e$ carry no informational load: their appearance is entirely governed by the nature of the preceding element in the clause. Added to the fact that they are small phonological words (single unstressed vowels), they are perhaps easily omitted as a result. The progressive particle, on the other hand, differs in this regard, since it is the marked of the progressive aspect, together with the habitual form of the verb bezañ 'to be'. One might therefore expect that this particle would be less susceptible to omission; however, as Figure 1 shows, the progressive particle is frequently omitted by the senior adults in the present study, who omit it in over 80 per cent of utterances $(99 / 115)$, despite the fact that it carries some meaning.

This contrasts completely, however, with the younger generation of speakers, both the young adults and the children, who omit the particle in only a small proportion of their utterances ( $23 \%$ and $24 \%$, respectively), and the difference between the generations is statistically significant: $\chi^{2}(1, N=520)=152.98, p \leq 0.0001$. The younger generation is almost the inverse of the older generation with respect to particle usage. It is possible that because the children and young adults see Breton written on a daily basis, and are very familiar with the written form of the language, they tend to reproduce it more closely in speech, unlike the senior adults we investigated, who were unable to read and write Breton. What is clear is that this is a feature of Breton on which the older and 
younger generations are divided, quite possibly as a result of the different processes of language acquisition that the two generations have experienced.

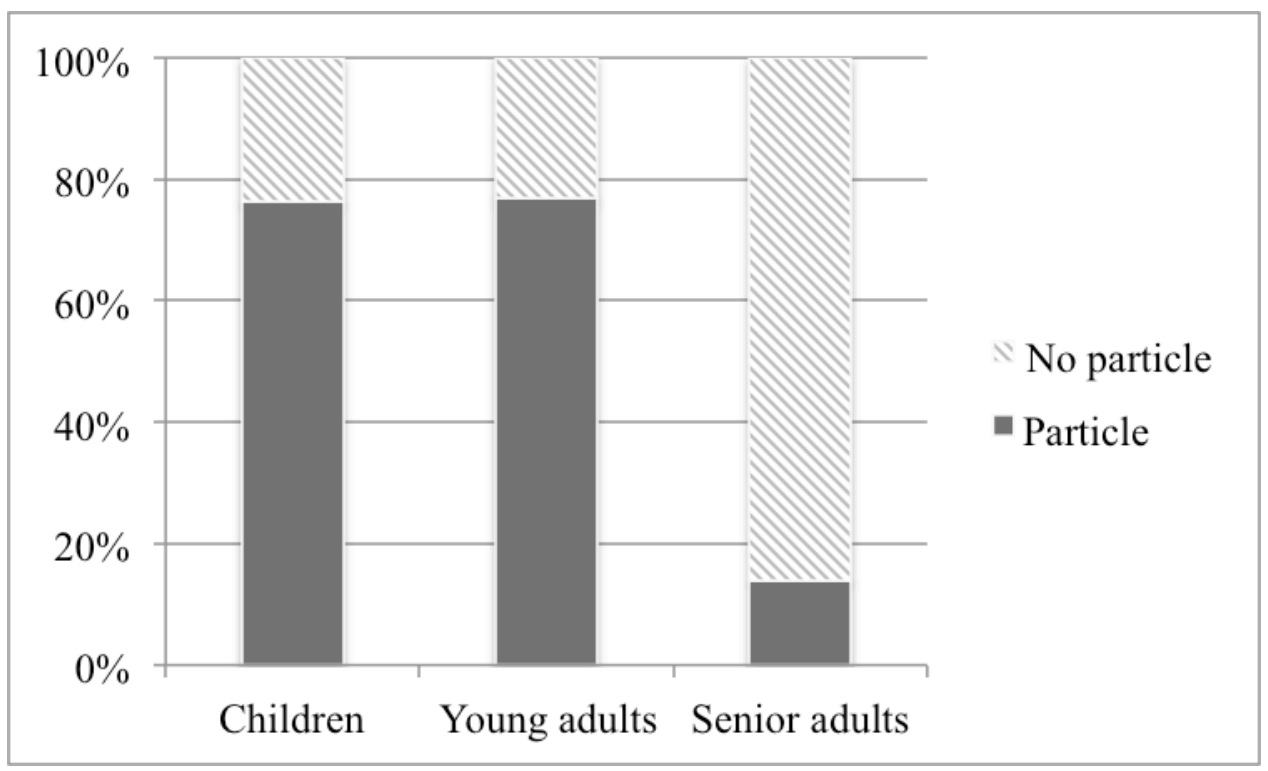

\section{Figure 1}

Particle usage

These data might lead to certain predictions about mutation usage. For example, it might be expected that the mutation usage of the two groups making up the younger generation will be similar, since their use of the particle is similar, and that it will be different from the older generation. Equally, it is possible that the increased use of the progressive particle by the younger generation might correlate with a decrease in the use of the mutation that follows, since it renders the mutation itself redundant as a marker of the progressive. This would also be in keeping with some descriptions of Neo Breton, which, as discussed above, claim that one of the features of this variety is the loss of morphosyntactic marking such as mutation. These predictions will be kept in mind in the discussion to follow. 


\section{ANALYSIS OF THE DATA: MUTATION USAGE}

\subsection{Adults}

The discussion can now turn to an examination of the data for mutation usage. Before addressing the question of how the transmission gap might be affecting the usage of mutation among younger Breton speakers, we must first investigate whether the older generation of speakers in this part of Brittany are actually using mutation as described in accounts of the language. Breton has undergone a rapid decline, and all speakers are now bilingual, which might result in the loss of certain features (see, e.g. Dressler 1991). However, the data clearly show that the senior adults are proficient in the use of the mixed mutation following the progressive particle. Of a total of 108 utterances, 60 have the mixed mutation, and 42 have ambiguous lenition, as in (10) and (11).

(10) Mixed mutation - speaker K

emañ [o] tigeriñ an nor

be.SIT.3SG [PRT] open.PROG DET door

'He/she is opening the door.'

(11) Ambiguous lenition - speaker J

emañ $[\mathrm{o}]$ c'hortoz an te da zont yen

be.SIT.3SG [PRT] wait.for.PROG DET tea to come.VN cold

'He/she is waiting for the tea to cool.'

Only one utterance has incorrect lenition (the transformation of $/ \mathrm{d} /$ into $/ \mathrm{z} /$ ) and only five omit the mutation altogether, which is a very small proportion of the whole. Since the departures from the usual use of mutation make up such a small proportion of the data, it is impossible to find any definite reason for why these instances lack the expected mutation. 
In light of the claims regarding Neo Breton, it would not be surprising to find that the young adults, as members of the new generation of speakers, might not be proficient in the use of this mutation. In fact, however, the young adults' use of mutation is very similar to that of the senior adults, as Figure 2 shows.

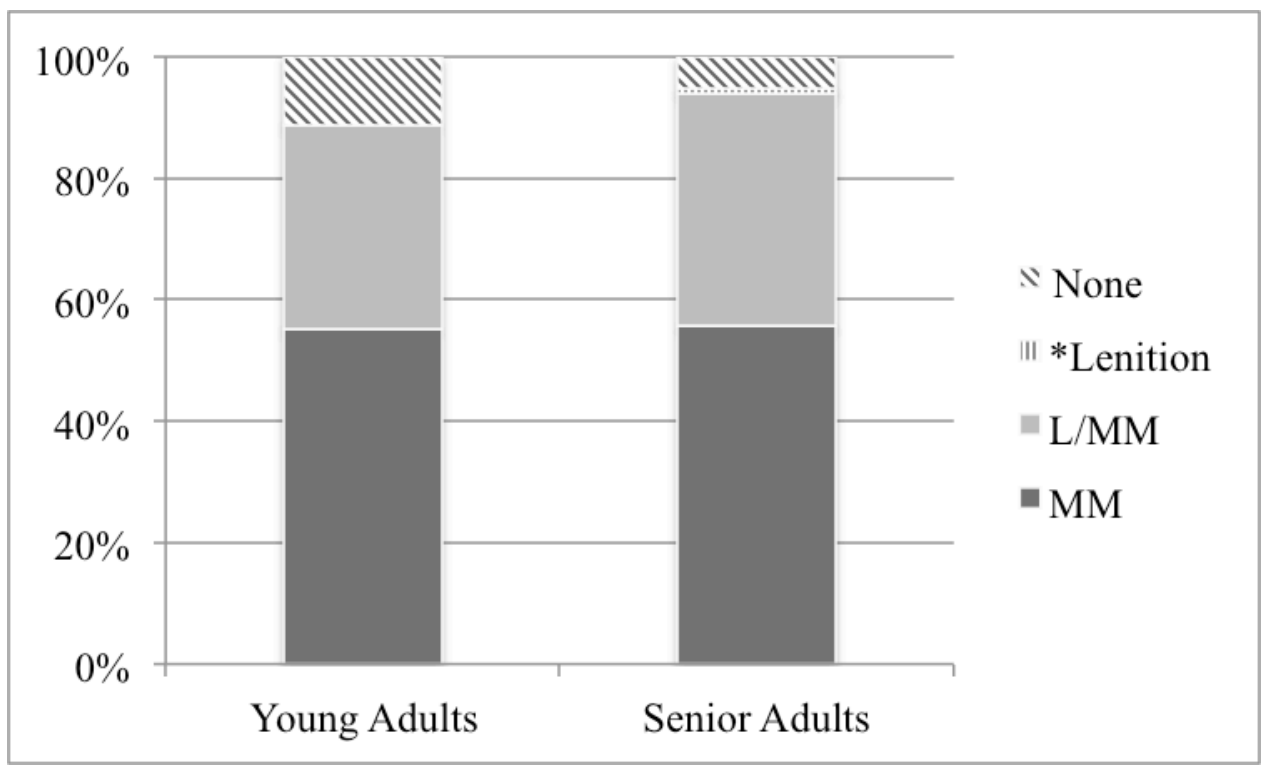

Figure 2

Mutation usage: senior and young adults

The young adults omit the mutation slightly more frequently than the senior adults do, but a chi-squared test indicates that the difference between the two groups of adults is not significant. Of the 152 utterances with the appropriate context, the young adults use the mixed mutation in 82 utterances, and ambiguous lenition in 52 utterances, as in (12) and (13).

(12) Mixed mutation - speaker L

Annick a zo [o] tañsal

Annick PRT be.UNIN [PRT] dance.PROG

'Annick is dancing.'

(13) Ambiguous lenition - speaker D 


$$
\begin{aligned}
& \text { ar plac'h-se [a] zo } \quad \text { o } \\
& \text { DET girl-DEM [PRT] be.UNIN PRT }
\end{aligned}
$$

The young adults never use incorrect lenition, but omit the mutation entirely in 18 utterances, as in (14).

(14) No mutation - speaker E

$$
\begin{array}{lll}
\text { o } \quad \text { gwriat emañ } & \text { Soazig } \\
\text { PRT } & \text { sew.PROG be.SIT.3SG } & \text { Soazig } \\
\text { 'Soazig is sewing.' }
\end{array}
$$

Looking more closely at the data for the young adults, a little more can be said about the instances where the mutation is omitted entirely. In a few cases, the speaker pauses between the progressive particle and the verb, perhaps taking a moment to recall the appropriate word in Breton, which may explain why the mutation is omitted: the triggering environment is too far away. Additionally, eleven of the cases where mutation is omitted come from a single speaker, E, who never uses the mutation with /b/-initial or/gw/-initial verbs: her data include bale 'to walk', bageal 'to sail', gwriat 'to sew', gweladenniñ 'to visit' and gwerzhañ 'to buy', and none of them is ever mutated following the progressive particle. It is difficult to say whether this is simply a coincidence, or if there is something about these initial segments that is relevant. E also omits the mutation on a few instances of debriñ 'to eat' and mousc'hoarzhin 'to smile'. It is unclear why speaker E omits the mutation more often than the other young adult speakers, as there is nothing in her linguistic background that would suggest she is different from them in some way. Perhaps she uses Breton a little less often in her daily 
life than the other speakers, or even found the task more artificial than the others did, and therefore produced less fluent Breton.

As mentioned above, the motivation for the category ambiguous lenition lies in the fact that for all consonants but /d/, it is impossible to distinguish the mixed mutation from lenition. However, this clearly results in a bias in the data: if speakers manage to use very few /d/-initial verbs in their responses, the proportion of their utterances with the mixed mutation will appear very low, while ambiguous lenition may still be very high. Given that senior adults practically never use incorrect lenition (the transformation of $/ \mathrm{d} /$ to $/ \mathrm{z} /$ ), and the young adults never do, it seems that this distinction is unnecessary for their data: there is no reason to assume that when they mutate $/ \mathrm{b} /, / \mathrm{g} /, / \mathrm{gw} /$ and $/ \mathrm{m} /$ they are not using the mixed mutation.

In addition to this, some senior adult speakers seem to have additional evidence that they are unambiguously using the mixed mutation following the progressive particle. Recall that in some dialects of Breton mixed mutation of consonants such as $/ \mathrm{b} /$ and $/ \mathrm{m} /$ may not produce exactly the same result as lenition - in the northern dialects, for example, /m/ becomes /f/, not /v/. Jackson (1967: 342) writes that in central and northeast Kerneveg (and the far north of Gwenedeg) the mixed mutation form of $/ \mathrm{m} / \mathrm{is} / \mathrm{h} /$. The roots of this development are unclear, but for two of the speakers in this study, $\mathrm{K}$ and QN (a married couple), this is the form they use for mutated $/ \mathrm{m} /$ with the verb $m o n t$, 'to go'. This is in contrast to the $/ \mathrm{m} />/ \mathrm{v} /$ of lenition, and strongly supports the fact that these speakers are using the mixed mutation, quite separately from lenition. None of the young adult speakers do this, which is as expected, given that they have learnt the standardised Breton taught in schools. 


\subsection{Children}

The data discussed up to this point have indicated that there is not a large gap between the two adult generations of Breton speakers in terms of mutation use: the young adults are just as proficient as using the mixed mutation following the progressive particle as the senior adults. In contrast, however, the children are far from being proficient in the use of the mixed mutation. Of a total 226 utterances, the children use the mixed mutation in only 32 cases, and ambiguous lenition in only 28 (see examples (15) and (16))

(15) Mixed mutation - speaker CG

n’ emañ ket o tañsal

NEG be.SIT.3SG NEG PRT dance.PROG

'He/she is not dancing.'

(16) Ambiguous lenition - speaker AJ

an den a zo [o] vousc'hoarzhin

DET man PRT be.UNIN [PRT] smile.PROG

'The man is smiling.'

Another striking contrast with the data from the adults is the children's use of incorrect lenition (as in (17)), in 41 utterances.

(17) Incorrect lenition - speaker BK

emañ al labous-ed o zebriñ

be.SIT.3SG DET bird-PL PRT eat.PROG

'The birds are eating.'

The remaining utterances, forming the largest proportion of the data, exhibit no mutation at all, and examples are given in (18a) and (18b). 
(18) No mutation

(a) Speaker EL

ar plac'h zo [o] debriñ ur skornenn

DET girl be.UNIN [PRT] eat.PROG DET ice.cream

'The girl is eating an ice-cream.'

(b) Speaker BK

Annick emañ ${ }^{7} \quad$ o bale gant ur plac'h

Annick be.SIT.3SG PRT walk.PROG with DET girl

'Annick is walking with a girl.'

The difference between the children and adults' use of mutation is shown in Figure 3, and is significant: $\chi^{2}(3, N=488)=241.07, p \leq 0.0001$.

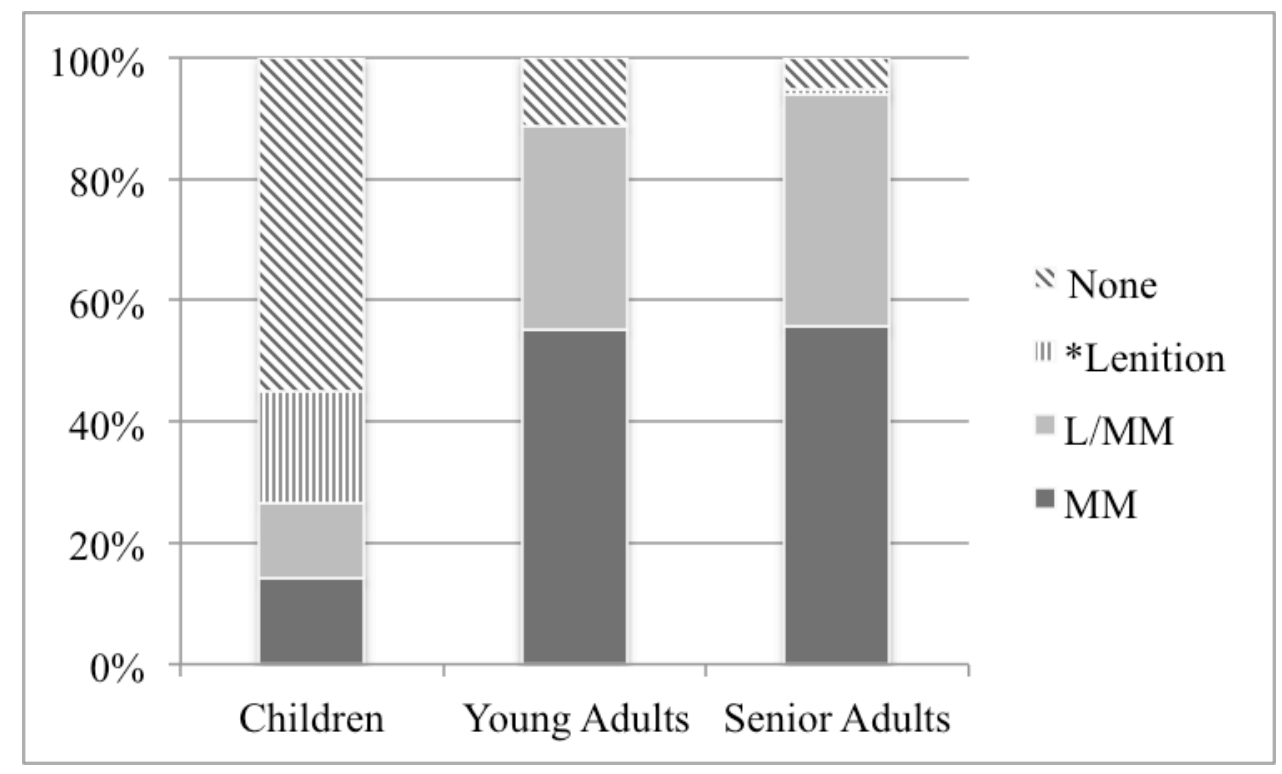

Figure 3

Mutation usage: adults and children

It is clear from the children's widespread use of incorrect lenition that they have not acquired the mixed mutation systematically - they may be aware that some sort of mutation is required in the context of the progressive particle, but they are overusing 
lenition, the most common mutation, and therefore perhaps the one they have been most exposed to.

The question then arises as to what, if anything, conditions the children's use of this mutation, and whether any factors affecting their usage can be observed. All of the children use mutation at least some of the time, although there is a large range in usage, from EL, who uses mutation in this context only once (of 31 utterances), to T, who during the second fieldwork visit, used some form of mutation in just over half of utterances containing this context (12 of 23). The data for the children, separated by schooling type, are presented in Figure 4. Table 4, with full details of the children's usage, presented speaker by speaker with raw numbers, can be found in Appendix A.

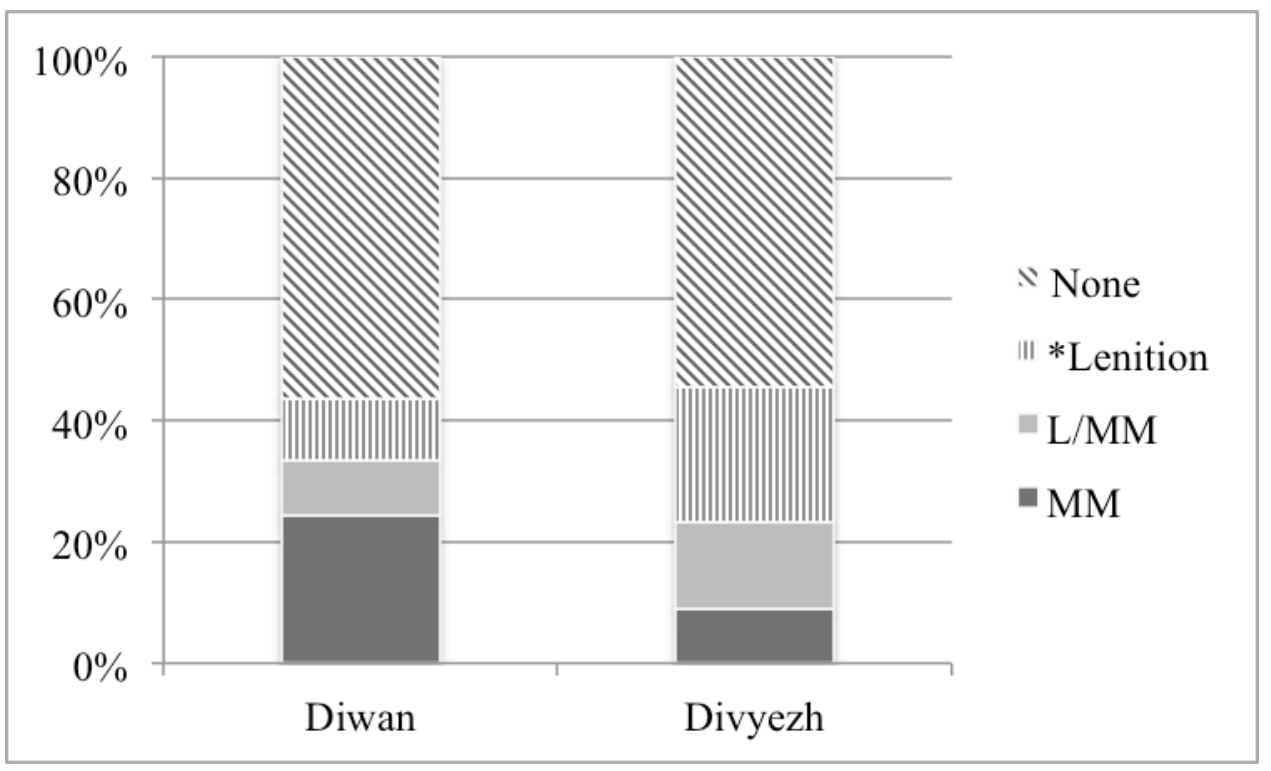

\section{Figure 4}

Children's use of the mixed mutation

It seems likely that age, first of all, is a factor in the use of the mixed mutation. B and $\mathrm{T}$ are the oldest children in the study, and are also in the same year group at school. They both use the mixed mutation at least some of the time (B: $26.1 \%$, T: $35.1 \%$ ), and more 
than most of the other children. $\mathrm{T}$ also uses ambiguous lenition (10.8\%), and they both use a small amount of incorrect lenition (B: 8.7\%, T: 8.1\%). In addition to this, the youngest speaker, A, is B's younger sister. She attends the same schooling system as he does, and therefore shares the same linguistic environment at home and at school, but does not use the mixed mutation at all - she seems therefore to be a few years behind her brother in terms of her linguistic development, as would be expected.

Further evidence for this can be seen from the use of the mixed mutation by speakers A, B and T in 'real time', that is, at two separate points in their lives. Due to constraints on which schools would accept fieldwork visits on each occasion WEconducted the fieldwork, only the three Diwan children were available to be interviewed during both fieldwork visits, first in March 2010, and secondly in October 2011. For these three speakers, then, this sheds a little light on how their mutation usage has developed over the course of eighteen months. As Figure 5 shows, the data indicate that A and T (but not B) seem to be using mutation to a greater extent in this context as they have grown older. T not only uses more mutation overall in the second fieldwork visit, but the proportions of mutation usage have also changed: he is using the mixed mutation $(d>t)$ in a greater proportion of utterances, and incorrect lenition in a smaller proportion of utterances. 


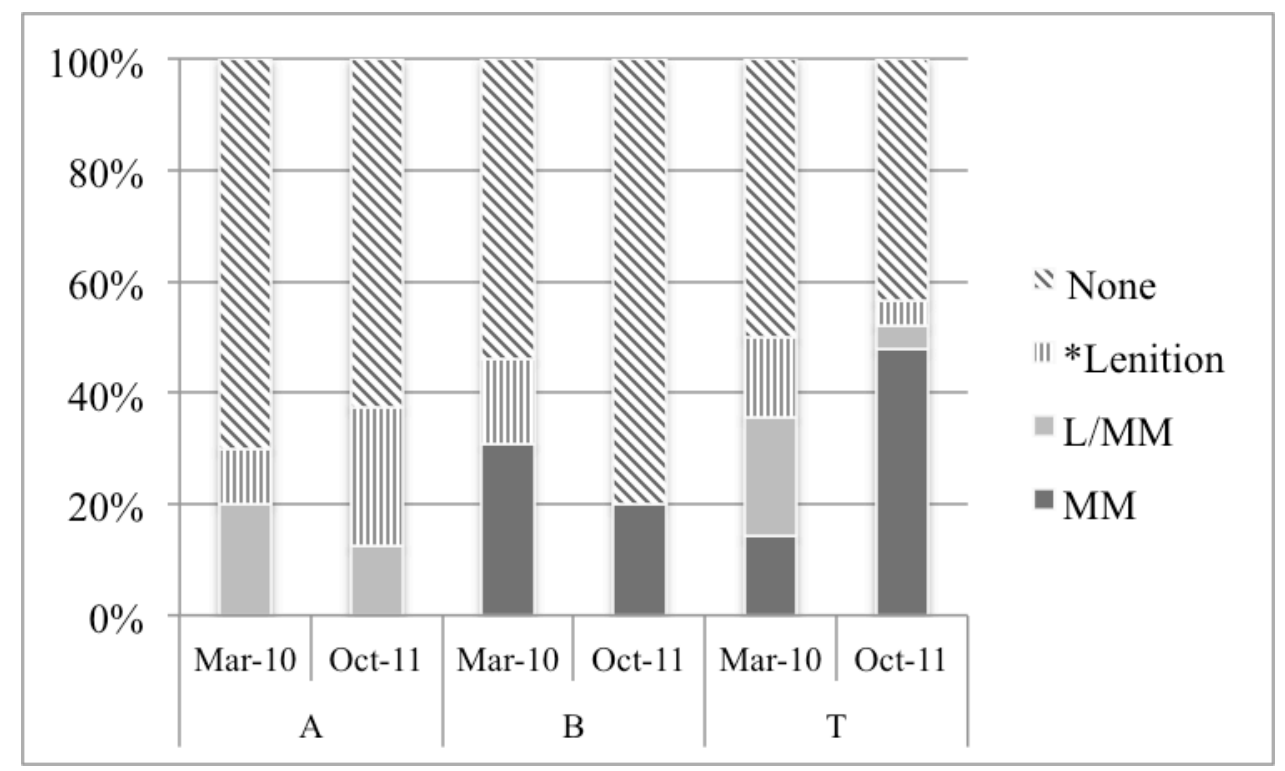

\section{Figure 5}

Changes in mutation usage over 18 months: A, B and T

It is not at all surprising that age should be a factor in the children's use of mutation. Language development is linked to cognitive ability, and it is expected that children's proficiency in language will develop as they grow older. Studies of Welsh mutation have found similar results, and so support this theory. For example, Gathercole and Thomas (2005) examined the acquisition of the Welsh soft mutation in gender-specific contexts, and found that older children were more proficient in the use of the mutation than younger children.

However, this trend is not observable in the data from speaker B, for whom the reverse is true. Although he is eighteen months older by the time of the second fieldwork visit, B here produces both fewer instances of mutation overall, and a smaller proportion of utterances with the mixed mutation (although there are also no instances of incorrect lenition in his data from the second fieldwork visit). This seems to undermine the idea that the children's use of mutation improves as they grow older. However, there may be another factor at work here: at the time of the second fieldwork 
visit, in October 2011, both speakers B and T had moved school level, from the French collège (age 11-15) to the lycée (age 15-18). The Diwan school system mirrors this: the children can go from the skol (age 2-11) to the skolaj (age 11-15) and then to the lise (age 15-18). However, there are many more skolioù Diwan, which cover only primary education, than there are secondary schools: there are only six skolajoù in the whole of Brittany, and just one lise. This is in Carhaix, which is about 50 kilometres from Quimper, and would necessitate boarding for speakers B and T. As a result, both speakers chose to leave Diwan schooling and had started to attend normal French lycées in Quimper. This meant that at the time of the fieldwork in October, B had hardly spoken Breton at all for over three months, since the end of the previous school year in June. He had difficulty at times recalling Breton words, and hesitated frequently when speaking. It is possible that this is why he appears less proficient at using mutation than eighteen months earlier, when the reverse would be expected.

The question then arises, however, as to why this only seems to be a problem for B, and not for $\mathrm{T}$, who is more proficient in his use of mutation during the second fieldwork visit, despite leaving the Diwan schooling system three months earlier. T reported, however, that he continued to use Breton with his friends from the Diwan school, some of whom had continued to the lise Diwan in Carhaix, and so boarded there during the week, but came home at weekends. This meant that he was still actively using his Breton, even though his schooling was now entirely in French. Dorian (1980) reports that the attitude of individual speakers towards obsolescent languages is central to their ability to use these languages. She found that the speakers whom she termed 'laggard semi-speakers', who continued to use the obsolescent language to some extent despite being somewhat removed, either geographically or generationally, from the rest of the 
speakers, were united in their positive attitude towards the language, and their desire to learn to speak it. When speakers want to continue to use the language, they are much more likely to be able to do so - as T's data seem to suggest.

The second factor at work in the children's use of mutation is that of schooling type. Speakers B, T and A all attend Diwan schools, while the other speakers attend the staterun Divyezh stream. The first indication that the type of schooling seems to be having an effect on the children's proficiency in using mutation comes from speaker A, who, as mentioned above, is the youngest of all the children, and attends the Diwan school. Despite the fact that on both fieldwork visits she is younger than the children at the Divyezh schools (all aged 10 or 11 at the time of interviewing), she uses mutation more than some of them.

Looking at the groups of Diwan and Divyezh children, as in Figure 4 above, this pattern becomes even clearer. The Diwan children use the mixed mutation in a greater proportion of utterances than the Divyezh children do, and the Divyezh children also use incorrect lenition much more than the Diwan children do. Indeed, some children (AJ, BK, EL and Y, as well as A) seem to use only incorrect lenition and ambiguous lenition (or omit the mutation entirely) in this context, and never use the mixed mutation. It is perfectly possible, at least, that some children are using only lenition, and not the mixed mutation, following the progressive particle - and of course among the younger generation there is no distinction between the mutated forms of $/ \mathrm{b}, \mathrm{m}, \mathrm{g}, \mathrm{gw} /$ in lenition as opposed to the mixed mutation. A chi-squared test shows that the difference in schooling types is significant: $\chi^{2}(3, N=225)=13.92, p \leq 0.003$.

Studies of mutation in Welsh have found similar results with regard to schooling: the type of schooling seems to be less influential than other factors in the children's use of 
mutation. Gathercole and Thomas (2005) found that younger children from Welsh-only schools were somewhat more proficient at using mutation than their peers at WelshEnglish or English-only schools, but that the difference faded as the children grew older. This seems to fit in with the findings from the young adults: if schooling were so influential as to permanently influence speakers' use of mutation, we would expect to see this reflected in the young adults' usage based on their linguistic background. However, as earlier discussion has shown, this is not the case. The difference in mutation usage based on schooling type must therefore be lost as children grow older. Although age and schooling play a role in the children's proficiency at using mutation, there is still some interspeaker variation that cannot be explained using these factors. CG, F and FM all use the mixed mutation at least some of the time, and Y rarely omits the mutation entirely. However, AJ uses mutation much less, and EL hardly at all. To some extent, this seems to be due to individual speakers' proficiency in different areas. EL speaks very fluently, but her use of mutation is almost non-existent. This can be seen in her mutation use generally, not just the verbal mutation being examined in this chapter: although she occasionally applies the rule for lenition of feminine nouns following the article, she never lenites nouns following daou/div 'two'. It seems that she has not really acquired any sort of system of initial consonant mutation.

Speaker F is particularly interesting: although she attends a Divyezh school, she also speaks Breton with her grandmother, who learnt Breton as a child and as her first language. It seems that children who speak Breton with a family member may be more proficient in their use of mutation than their peers. F uses the mixed mutation more than might be expected given her schooling (22\%), and this could be linked to her linguistic 
background outside school. Unfortunately, there is not sufficient data for $\mathrm{F}$ for this to be completely clear, and the generalisation does not seem to hold true for AJ, who was identified as a speaker with additional input outside of the school. His use of mutation is better than that of EL, but he still lags behind some of his peers. Y rarely omits the mutation entirely, but uses a high proportion of incorrect lenition (55\%), making it unlikely that he has acquired the mixed mutation rule as distinct from the lenition rule. It is also not clear from his data whether he has acquired all of the verbs in their radical form, as well as in the lenited form. His use of verbal morphology shows confusion, and it is possible that he only uses the mutated forms of some verbs.

CG and FM, on the other hand, seem more proficient in their use of the mixed mutation, despite being at a Divyezh school. Neither of them reported speaking Breton with anyone at home - FM's response to the question was that he spoke Breton 'pas trop' at home, while CG said that he spoke Breton 'un peu' at home. It is therefore difficult to say why these two speakers use the mixed mutation more than their peers at the Divyezh school, as there is nothing about their linguistic background which would explain their greater proficiency in mutation. Of course, since the children were selfreporting on their language use at home, it might be that their responses are not very accurate, but it is impossible to judge this. It seems, on the whole, that some of the children have simply managed to acquire the rule for the mixed mutation following the progressive particle, including /d/ to /t/, at an earlier stage than others.

In summary, then, the following patterns can be observed. The older speakers use the mixed mutation following the progressive particle as expected: there are very few instances in which they omit the mutation, and they barely use lenition in place of the mixed mutation at all. The young adults are much the same: for the most part they use 
the mixed mutation as the senior adults do, with the exception of one speaker, E, but it is unclear why her usage is different from that of her peers. The children present a much more complex picture. Their use of the mutation seems to be conditioned by a number of extra-linguistic factors: age, type of schooling and possibly additional Breton input. However, there also appears to be a noticeable amount of interspeaker variation that cannot be explained using these factors, and so it seems that some speakers are simply more proficient at mutation use than others, and are closer to acquiring the mutation rule than their peers.

\section{ACOUSTIC MEASUREMENTS}

The discussion to this point has assumed that the distinction between the mutated and non-mutated forms of each consonant is straightforward; that is, that when speakers use the mixed mutation following the progressive particle, they are producing a different phoneme from the one they would use if the progressive particle were not present. This is a crucial aspect of initial consonant mutation: the consonants involved are separate phonemes in the language, and this is therefore not allophony. However, the nature of the Breton situation may leave this assumption open to question: since all speakers are now bilingual in French and Breton, and the younger generation are heavily Frenchdominant, we might observe changes in the realisation of consonants in mutation contexts. The children are not proficient in the use of the mutation - might this be because they are not distinguishing between the phonemes in this context, for example? This section therefore examines the acoustic properties of the consonants involved in the mixed mutation, focusing on the alternation between the radical /d/ and the mutated $/ t /$. This is for a number of reasons. First, the mixed mutation of $/ d /$ is the crucial signal that the speaker is performing the mixed mutation, rather than lenition - the mixed 
mutation of the other voiced stops and the cluster/gw/ is identical to their lenited forms, particularly for the younger generation, and for at least some speakers from the older generation. Secondly, the distinction between a stop and a fricative is more acoustically and perceptually salient - there is not the same need to measure the consonants involved. For this reason, the instances of 'incorrect lenition', where /d/ is transformed to /z/, are not measured. Thirdly, it seems likely that the transformation of $/ \mathrm{d} /$ to $/ \mathrm{t} /$ might be more difficult for the children to acquire, since this mutation is in several ways the 'odd one out': it is the only one that differs from lenition, and is in fact the same transformation as found in provection, a type of mutation not normally found on verbs (and therefore perhaps unexpected). Provection also exhibits a reduction in sonority, in contrast to the other types of mutation found in Breton.

Added to this, it has been suggested that lenition is expanding in terms of its applicable contexts, at the expense of other types of mutation. Well-attested examples include the replacement of spirantisation by lenition following the numerals tri/teir 'three (M/F)', pevar/peder 'four (M/F)' and nav 'nine' (Favereau 1984; Press 2009; Stephens 1993; Timm 1985), but this is by no means the only instance of such a change. In his work on language attrition among Breton speakers, Dressler $(1972 ; 1991)$ writes that the decay of spirantisation tends to precede that of lenition, and that lenition largely replaces spirantisation among weaker speakers, that is, generally those born after the end of the Second World War. He suggests that since lenition is triggered in the greatest number of contexts, and affects the greatest number of consonants, it is in a sense the 'default' mutation. Dorian (1973) found a similar situation among speakers of East Sutherland Gaelic: younger speakers tended to generalise lenition in forming the passive 
instead of maintaining a more complex system that also involved nasalisation (Dorian 1973: 420).

This invites the question of whether the expansion of lenition is simply a symptom of language obsolescence. While the wholesale replacement of spirantisation by lenition among what Dorian would term 'semi-speakers' (Dorian 1977) seems likely to be a result of language attrition, there is evidence that some of the expansion of lenition in Breton may be something else. Hennessey (1990) writes that the change from lenition to spirantisation is not an indication of the decline of the language, but rather an instance of regular change, and one that has been in progress since the eighteenth century. It is attested in the Atlas Linguistique de la Basse Bretagne (Le Roux 1924-1963), and was well-advanced by this date. Hennessey proposes the following implicational model for the replacement of spirantisation by lenition: tri/teir 'three $(\mathrm{M} / \mathrm{F})$ ', pevar/peder 'four $(\mathrm{M} / \mathrm{F})$ ', nav 'nine' < ma 'my' <o 'their', hon 'our' < he 'her'.

Additionally, a similar development can be observed in Welsh. Awbery (1986) writes that many southern Welsh dialects are seeing an increase in the use of the soft mutation (which is equivalent to lenition in Breton), and a decrease in the aspirate and nasal mutations, which seem to parallel the tendencies found in Breton. In some cases the aspirate and nasal mutations are being omitted entirely, but in others they are being replaced by the soft mutation. These changes are not consistent in any one dialect: for each environment where the nasal or aspirate mutation would be expected, there has been change in some dialects, but not others. This therefore seems to be part of an ongoing change in the language.

All of the above factors make the mixed mutation of /d/ to /t/ particularly vulnerable, and therefore determining how speakers produce these phonemes is crucially important: 
if the children are receiving mixed input here, it is hardly surprising that they are finding this mutation difficult to acquire. This section examines the following questions: 1. Does the mutated /t/ have the same acoustic properties as the non-mutated /t/? Is mutated /t/ notably different from /d/?

2. When the children fail to mutate /d/, does this consonant have the same properties as a /d/ appearing in a non-mutation context?

3. What characterises / $/$ / and $/ \mathrm{d} /$ in Breton? Can we use this information to confirm speakers' use of mutation?

In order to answer these questions, measurements of the relevant consonants were taken. When the mutation substitutes a fricative for a stop, the acoustic differences are clear. However, the only feature that distinguishes $/ \mathrm{d} /$ and $/ \mathrm{t} /$ is that of voicing, and thus making the distinction is much more difficult. In stops, the distinction between voiced and unvoiced sounds is often not exclusively that of the presence as opposed to the absence of glottal vibration, since when there is a complete closure in the oral tract, little air is moving through the vocal folds (Ladefoged, 2005). In many languages, then, a difference in voicing is a combination of differences in closure duration, aspiration, voice onset time (the time between the release of the consonant and the start of the following vowel), and vowel length (Mikuteit \& Reetz 2007). It is not simply a matter of detecting vocal fold vibration to distinguish between /t/ and /d/, but is rather more complex. In this study, then, two measurements were taken for each mutation context: the length of the closure (closure duration) of the stop, and the length of the release. Relatively little work has been done on the acoustic properties of Breton, with two notable exceptions being Falc'hun's (1951) study of leoneg Breton, as spoken in BourgBlanc, a commune north of Brest, and Bothorel's (1982) study of the Breton of Argol, 
on the Crozon peninsula. In his seminal study, Falc'hun identifies four main variants of alveolar stops, which he labels $t, d, d d$ and $D$. This allows him to capture both a voicing distinction and, additionally, a contrast between fortis and lenis consonants, which he considers to be vital in the description of consonants in Breton. Fortis consonants are produced with a greater articulatory force than their lenis counterparts. The appearance of fortis as opposed to lenis consonants is largely dependent on the context: where the stop appears within the word, what follows it, and whether it is mutated.

Falc'hun reserves the symbol $t$ for the voiceless fortis stop, which, like $p$ and $k$, is found word-initially and word-medially. Word-finally, the contrast between voiced and voiceless stops is lost in Breton, since the voicing depends entirely on the following sound: voiced when the following sound is voiced, but otherwise voiceless. For example, mat, 'good' has a voiceless final consonant when pronounced in isolation, /ma:t/, but a voiced final consonant when followed by a vowel, as in mat eo /ma:de/, 'it is good'. Falc'hun therefore uses the capital italic $D$ to refer to the alveolar stop in this position, and notes that it is always lenis: only the voicing varies.

The fortis-lenis contrast is key to understanding the difference between Falc'hun's $d$ and $d d$. The single $d$ is used for the voiced lenis stop, which appears in two contexts: word-medially, and as the lenited counterpart of $t$. All word-initial consonants are fortis, which is why Falc'hun transcribes the voiced fortis stop as $d d$. It appears in word-initial position, but is never the result of lenition of $t$.

Although Falc'hun does not refer to the voiced fortis stops as geminates, his phonetic measurements show that they are overall longer than their lenis counterparts: the average length of $d d$, for example, is found to be $95 \mathrm{~ms}^{8}$, while $d$ is $56 \mathrm{~ms}$. The voiceless fortis stops are longer still, even in non-initial position: intervocalic $t$ is $108 \mathrm{~ms}$ on 
average. The following points therefore arise from this: intervocalic consonants are likely to be shorter than word-initial consonants, and the voiced stops that result from lenition are shorter than radical word-initial voiced stops. This also explains why the example of ar bal is likely not to be ambiguous in speech: in Falc'hun's terms we would expect ar bbal 'the ball' (unmutated) but ar bal 'the spade' (mutated).

As Falc'hun does not divide consonant length up into closure duration and voice onset time or release, his measurements do not give any indication of how these interact to distinguish voiced and voiceless stops in Breton. Bothorel's (1982) study, although much later than that of Falc'hun, does not refer to these measurements either, and distinguishes between / $\mathrm{t} /$ and /d/ purely in terms of voicing: 'Ces deux consonnes se différencient par le fait que [d] est manifesté, au bas du spectre, par une "barre de voix", indiquant son caractère sonore, alors que [t] est réalisé sourd"9 (Bothorel 1982: 114).

For our study, the consonants were measured using the speech analysis program Praat. For every speaker, each instance of the mixed mutation on a /d/-initial verb was isolated, unless the speaker had incorrectly lenited the consonant, resulting in an initial /z/. The closure duration and release of the stop were then measured. Instances where there was background noise, a pause between the progressive particle or preceding auxiliary and the verb, or no preceding vowel (for example, because the particle was omitted) were not included, because the start and end of the closure duration and possibly also the release could not reliably be identified. Examples of the consonants in the mutation context with the closure duration and release marked can be found in Figures 6 and 7. Both speakers are using the verb dañsal 'to dance'. The figures show part of the preceding particle (marked as $o$ ), the consonant in question $(/ \mathrm{t} /$ in Figure 6 
and /d/ in Figure 7), which is divided into closure duration (CD) and release (REL), and the start of the following vowel /ã/.

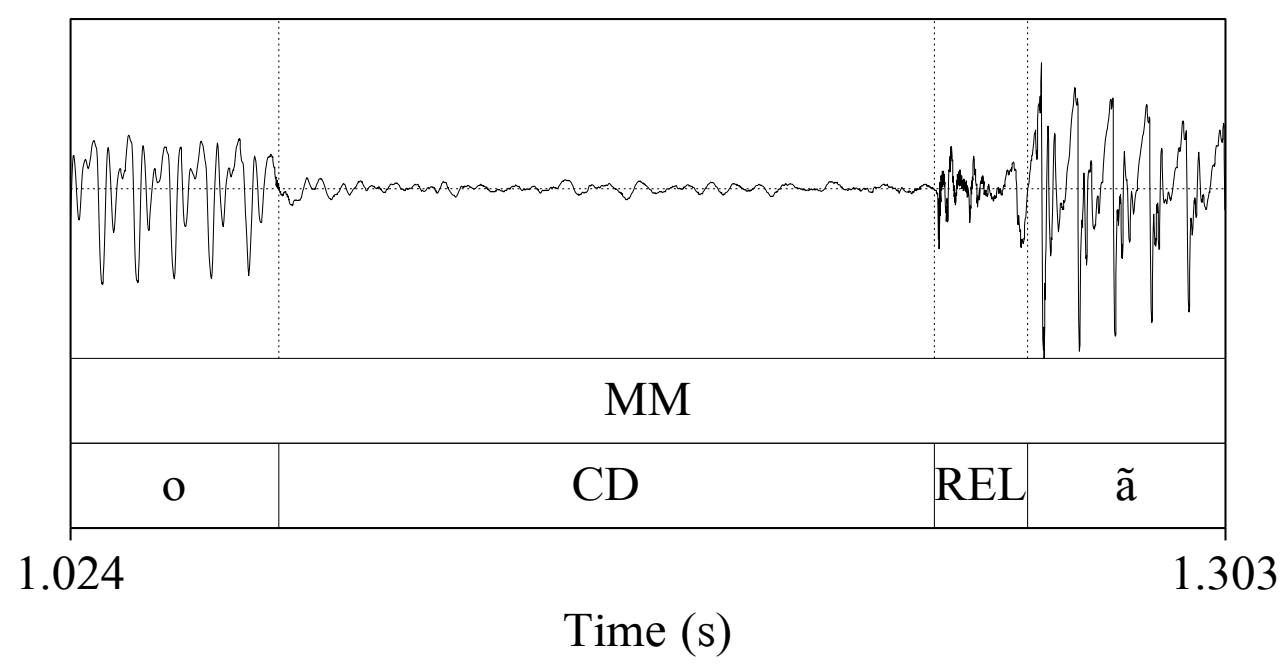

Figure 6

$/ \mathrm{t} /$ - Speaker I (mixed mutation)

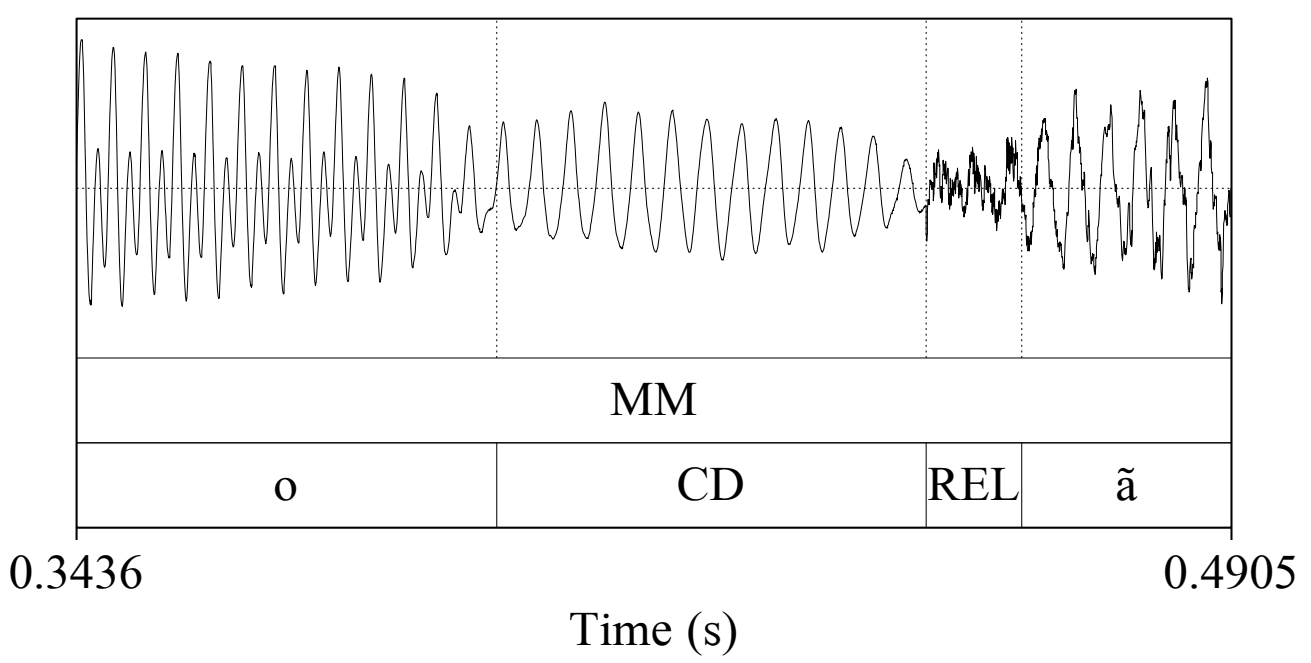

Figure 7

/d/ - Speaker CG (no mutation)

The expectation is that $/ \mathrm{t} /$ and $/ \mathrm{d} /$ in the mutation context should be significantly different from one another (in terms of their closure duration and release), but also that 
they should be the same as 'normal'/t/ and /d/; that is, the same phonemes as found in non-mutation contexts. Since there is no lenition involved, we do not expect to find a contrast between fortis and lenis voiced stops, in the way that Falc'hun (1951) describes. To address this issue, 'control' consonants were found for each speaker, with the stop appearing in a context where it would never undergo any sort of mutation. Where possible, the consonant was preceded by /o/, to mimic the conditions for the mixed mutation following the progressive particle; however, where this was not possible, contexts with other vowels, or simply other sonorants (such as the nasal $/ \mathrm{n} /$ ) were used. Our expectations, and how they relate to Falc'hun's findings, are summarised in Table 2.

\begin{tabular}{lll}
\hline Context & Falc'hun's finding & Expectation \\
\hline Underlying /t/( o tañva 'tasting') & $<\mathrm{t}>$ & {$[\mathrm{t}]$} \\
Underlying /d/ (dañsal a ran 'I dance') & $<\mathrm{dd}>$ & {$[\mathrm{d}]$} \\
Mixed Mutation /d/ > /t/ (o tañsal 'dancing') & - & {$[\mathrm{t}]$} \\
No mutation of /d/ (*o dañsal) & - & {$[\mathrm{d}]$} \\
\hline
\end{tabular}

Table 2
Comparison of Falc'hun's (1951) findings and current expectations. Falc'hun's findings are in angled brackets since they are not intended to be actual phonetic script.

It became clear even at the stage of measuring that there was another factor that would have to be considered when analysing the measurements of the consonants, namely, the nature of the following vowel. Consonants followed by a high front vowel (/i/ or /y/), very often had palatalisation or affrication - a process which is reasonably well-attested in Breton (e.g. Falc'hun 1951). This meant that the release of the consonant preceding a high front vowel was likely to be much longer than when the consonant preceded any other vowel. 
Analyses of variance were performed for both closure duration and release. The factors were Consonant Type (/t/ or /d/), Mutation (mutated or not mutated, i.e. 'control'), Group (senior adults, young adults, children) and Vowel Height (height of the following vowel: high or non-high) with Subjects nested under Group as a random factor.

For release, there were significant main effects of Consonant Type $(F(1,255.4)=$ 71.25, $\mathrm{p} \leq 0.0001)$, Group $(\mathrm{F}(2,53.62)=4.42, \mathrm{p} \leq 0.0167)$, and Vowel Height $(\mathrm{F}(1,250.4)$ $=79.43, \mathrm{p}<0.0001)$. Furthermore, the following interactions were significant: Consonant Type $\times$ Vowel Height $(F(1,251)=32.53, \mathrm{p} \leq 0.0001)$ and Group $\times$ Consonant Type $\times$ Vowel Height $(F(2,251.5)=3.63, p \leq 0.02)$. Paired comparisons showed that the senior adults were significantly different both from the children $(t=2.96, p \leq 0.0047)$ and from the young adults $(\mathrm{t}=-2.19, \mathrm{p} \leq 0.03)$ with respect to the length of the release. For closure duration, there was only a significant main effect of Consonant Type ( $\mathrm{F}(1$, 254.1) $=10.47, \mathrm{p} \leq 0.0014)$

Since Consonant Type is a significant factor for both release and closure duration, it is clear that $/ \mathrm{t} /$ and $/ \mathrm{d} /$ can be reliably distinguished, as shown in Figure 8 . Since Mutation (that is, whether the consonant appears in a mutation context, or a non-mutation context) is not a significant effect for release or closure duration, the mutated $[\mathrm{t}]$ (derived from $/ \mathrm{d} /$ ) did not differ from the regular $/ \mathrm{t} /$ in a non-mutated context. 


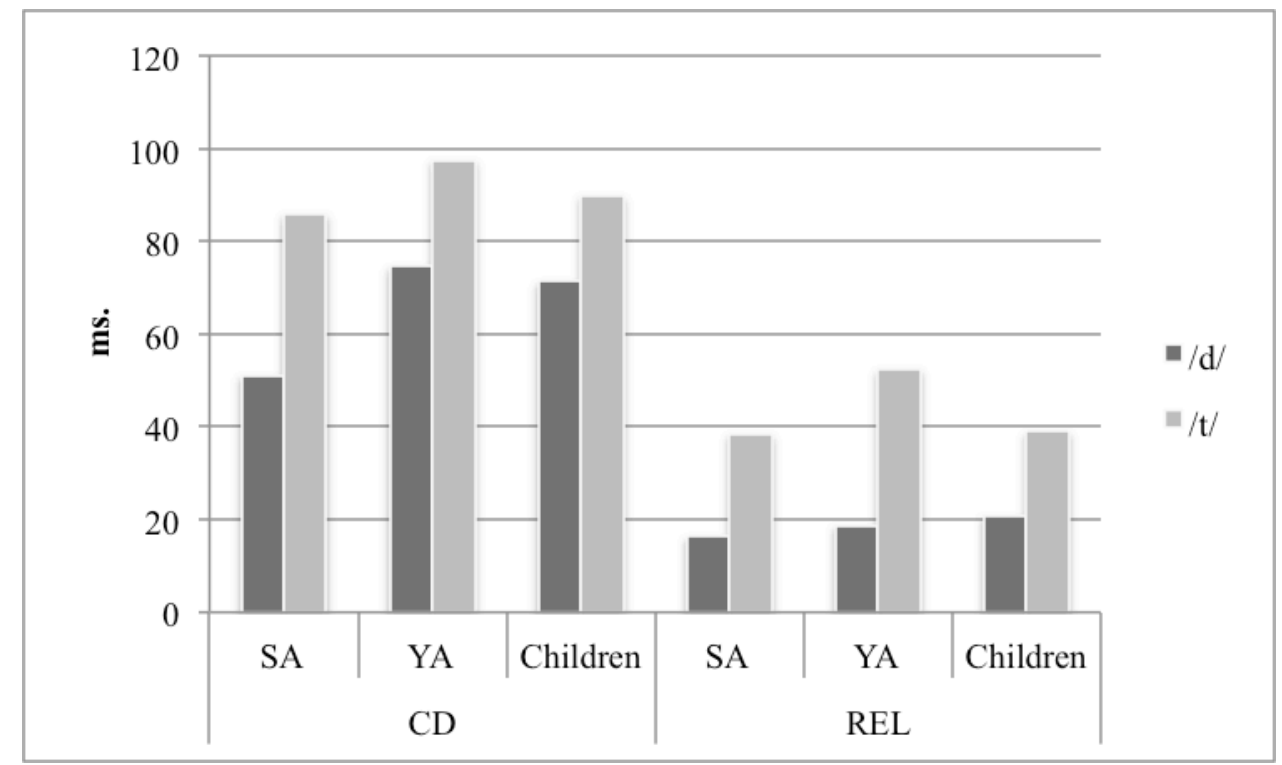

Figure 8

Closure duration (CD) and release (REL) of $/ \mathrm{d} /$ and $/ \mathrm{t} /$

Vowel height significantly interacts with the release of the consonant; i.e., mutated /t/ in the context of a high vowel has a significantly longer release and could almost be transcribed as an affricate. It also interacts with the effect of Group: the fact that Group is a significant effect for release shows that there is some difference between the three groups of speakers. Closer examination indicates that this difference is down to the release of /t/ before a high front vowel, due to the affrication that this causes. A paired comparison shows that the release is significantly longer for the children $(t=4.20$, $\mathrm{p} \leq 0.0001)$ and the young adults $(\mathrm{t}=-6.05, \mathrm{p} \leq 0.0001)$ than for the senior adults, as shown in Figure 9. The same is not true of the non-high vowel context, where there is no significant difference. There are no other significant differences between the groups. 


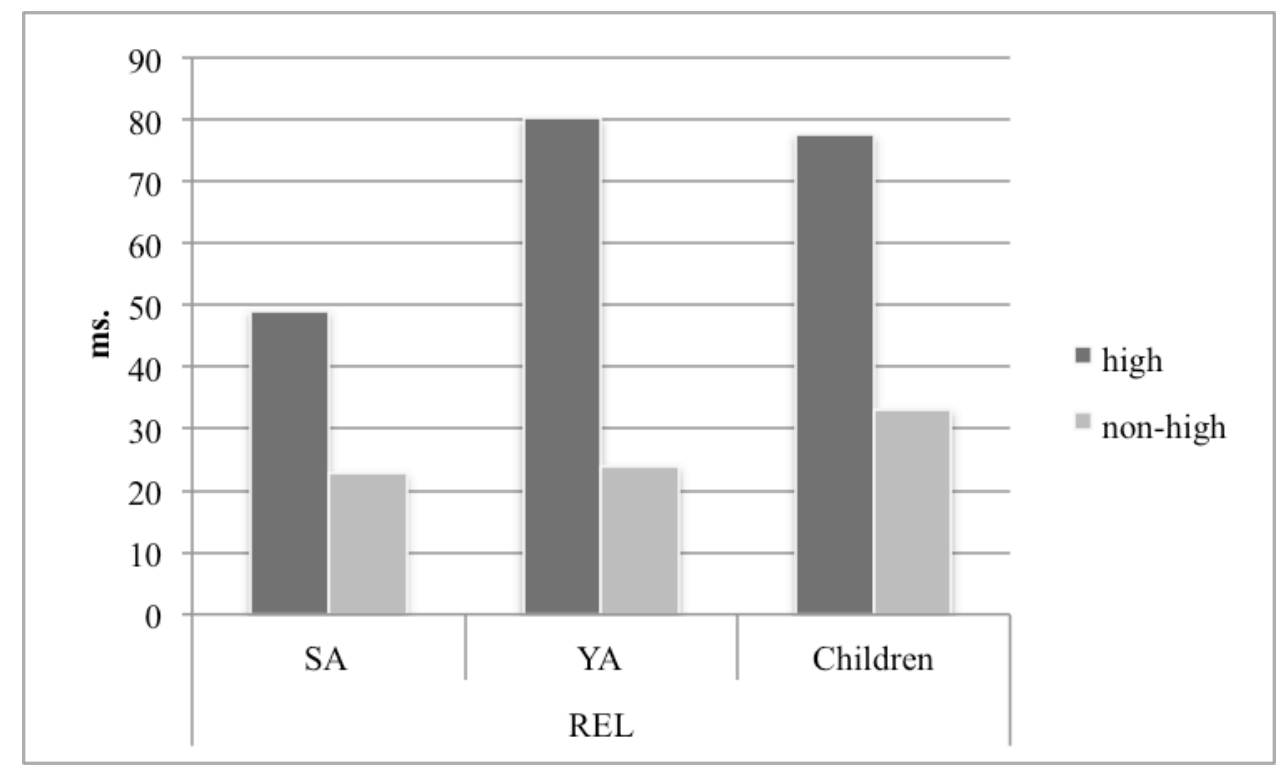

\section{Figure 9}

Release (REL) of /t/ in the context of high and non-high vowels

It seems, then, that the younger generation of speakers are increasing the tendency towards affrication when the consonant precedes a high front vowel. This appears to be a new sound change occurring only in Neo Breton. While palatalisation before high vowels is found in some varieties of French (Fagyal, Kibbee \& Jenkins 2006), this is not something that is very widespread, and it therefore seems unlikely that this could be due to French influence. Rather, we are witnessing a new development of assimilation in progress.

\section{DISCUSSION}

Our study has examined one particular usage of initial consonant mutation in the Breton of two generations of speakers. Initial consonant mutation is the process whereby the initial consonant phoneme of a word is replaced by another phoneme in certain morphosyntactic contexts, and the mutation under consideration here is the mixed mutation following the progressive particle (e.g. emaon o tañsal 'I am dancing', from dañsal 'to dance'). The data show that this instance of mutation is alive and well in both 
generations of Breton speakers, despite factors that might be supposed to lead to its decline: all Breton speakers are now also fluent in French, and younger speakers largely come from French-speaking homes and learn Breton through immersion schooling. The mixed mutation is also vulnerable to replacement by lenition, a more widespread form of mutation which closely resembles the mixed mutation, and which has been shown to be expanding at the expense of other types of mutation.

Despite the fact that Breton has experienced a gap in language transmission, our fieldwork data suggest that the young adults are just as proficient as the older generation in the use of the mixed mutation following the progressive particle. The adults in this study all use the mixed mutation in this context as expected, regardless of which generation they belong to, but the children have more difficulty. Not only are the adults accurate in using mutation, they rarely make errors in the use of the correct consonant. Furthermore, acoustic analysis of the key aspect of the mixed mutation, the change from /d/ to /t/ which distinguishes it most clearly from lenition, shows that the mutated form is significantly different from the unmutated form in terms of its closure duration and the length of release. Further measurements confirm that the mutated form, $/ \mathrm{t} /$, is not significantly different from the phoneme / $t$ / found in other, non-mutation contexts, and thus mutation can be considered a form of neutralisation. That is, there is no distinction between the consonants in question in terms of their acoustic properties. At least according to these data, it appears that Breton is a 'voicing' language, contrasting a fully voiced /d/ (with pre-voicing) and a short-lag VOT in /t/ (cf. Reetz \& Jongman 2009: 98). These acoustic cues are similar to those found in the Romance languages (Lisker \& Abramson 1964). 
Within the younger generation, however, there is a contrast between the young adults, who use the mutation proficiently, and the children, who do not. Recall that the children are certainly able to maintain the distinction between mutated and unmutated consonants, for instance a / $/$ / and a $/ \mathrm{d} /$ in contrastive words; thus, the lack of mutation in the verbs must be an effect of language acquisition. Although continued input in Breton is clearly an issue for children acquiring the language, the data for the young adults show that they have acquired Breton mutation despite this, which suggests that at least some of the children will eventually be able to use mutation in the same way that both groups of adults do. This in turn implies that the differences between the generations, and the effects of the transmission gap, are smaller than might have been supposed, at least with regard to mutation in this context.

In the use of the triggering particles themselves, however, there is a very clear crossgenerational difference. The senior adults omit the particles in the majority of utterances (maintaining the mutation), while the young adults and children do almost the opposite, retaining the particles in the vast majority of cases. Table 3 gives a summary of how the different groups and generations mark the progressive aspect: the senior adults largely use only mutation, the children almost always use the particle but do not use the mutation proficiently, and the young adults use both the particle and the mutation.

\begin{tabular}{llll}
\hline & Senior Adults & Young Adults & Children \\
\hline Use of particle o & Largely omitted (in & Largely retained (in & Largely retained (in \\
& $86.1 \%$ of cases) & $77.0 \%$ of cases) & $76.3 \%$ of cases) \\
\hline Mixed mutation of & Always & Always & Variable \\
progressive verb & & & $\begin{array}{l}\text { proficiency: } \\
\text { confusion with } \\
\text { lenition, frequently } \\
\text { omitted entirely }\end{array}$ \\
\hline
\end{tabular}

Table 3

Cross-generational marking of progressive aspect 
Specifically, it seems that mutation, or at least this particular instance of mutation, takes considerable time and a lot of exposure to Breton to acquire. As Hennessey (1990) writes, the replacement of other mutations by lenition is not a symptom of language decline, but rather part of the regular process of change in the language. It might be expected that the young adults and the children, would be part of the same 'linguistic generation' in terms of the use of mutation, but it is not the case. Instead, the difference between these two groups suggests that the acquisition of mutation takes place late in the acquisition of the language as a whole, and is also quite a slow process. Data from the late nineteenth century support this: Le Dû (1986) writes that at that time spirantisation was only completely mastered by speakers when they were in their teens. It is not so strange to imagine that mutation in Breton, and particularly the mixed mutation, which differs from lenition, might now be acquired late in the children's development.

Evidence from Welsh also supports this: studies have found that the development of the mutation system in children continues beyond age ten (Thomas \& Gathercole 2007; Thomas \& Mayr 2010). Many of the children in these Welsh studies came from Welshspeaking homes, where one or both parents were first-language Welsh speakers. This is not the case for Breton, and none of the children in this study had even one parent who spoke Breton as a native language; many spoke no Breton at home at all. It is therefore not unreasonable to assume that the Breton mutation system is acquired at an even later age by Breton children than the Welsh mutation system among Welsh speakers.

One factor seems to emerge from this study as particularly important in the complete acquisition of Breton: continued input in the language, probably well beyond the early teenage years. This is something that Gathercole and Thomas (2009) also identify as a 
factor in minority language acquisition: they find that the level of retention of Welsh vocabulary is influenced by continued exposure to Welsh in adulthood. In this study, even the most proficient speakers among the children do not use mutation in the same way as the adults, and so clearly continued exposure to Breton is necessary to acquire the mutation rule. The comparison of the two oldest children, both of whom had ceased to be educated in Breton at the time of the second fieldwork visit, makes this particularly clear: B no longer used Breton very frequently, while T continued to meet his Breton-speaking friends, some of whom were attending the lise Diwan, and spoke Breton with them. There was a clear difference in proficiency between $\mathrm{B}$ and $\mathrm{T}$ in terms of mutation usage in the data from the second fieldwork visit.

Unfortunately, the opportunities for learning in Breton decrease as children become older, as mentioned above. While there are many Diwan primary schools, there is just a handful of skolajoù for 11 to 15 year olds, and only one lise for 15 to 18 year olds. The situation for the state-run Divyezh stream is equally restricted. Broudic (2010) writes that that the filière bilingue at the secondary level is often not bilingue at all; that is, there are not equal proportions of classes in Breton and in French, as there are at the primary level. Frequently Breton is reduced to just two or three hours a week, and as a result some parents choose to send their children to the Diwan schools at the secondary level. Only half of the children in primary Divyezh streams continue in these streams at the secondary level, and Broudic (2010: 203-204) suggests a number of reasons for this: secondary education is regarded as too important to have it taught in Breton; children want to stay at the same school as their friends; another, French-only, school is closer to home, among others. The result is that many children stop learning Breton aged 11, and even more stop learning Breton aged 15, like those in this study. 
In addition to the difference in particle usage, acoustical measurements allow us to observe a further new development in the Breton of the younger generation (both children and young adults), namely in the production of the voiceless stop /t/. An increase in affrication before high front vowels means that this stop has a significantly longer release for the younger generation than for the older generation. It seems unlikely that this is due to French influence. What we are seeing here is a type of pertinacity, whereby 'a rule or pattern may persist over time, though its realization may change' (Dresher \& Lahiri 2005: 75). The formation of the progressive in Breton continues to include the mixed mutation, but the degree to which the progressive particle (triggering that mutation) is used is different across the two generations. Likewise, the exact realisation of $/ \mathrm{t} /$ in some contexts is changing, but it continues to contrast with /d/. It is conceivable that some further sort of 'language change' may occur in Breton, whereby the mutation is eventually lost following the progressive particle, since the information it encodes is essentially redundant. However, although children need time to acquire the mixed mutation, it is not the case that they are omitting it entirely, and so it is also possible that the reverse will happen, and the tendency observed in the older generation, where the particle is lost in informal speech, will eventually continue among the younger speakers. 
APPENDIX A

\begin{tabular}{|c|c|c|c|c|c|c|}
\hline \multicolumn{2}{|l|}{ Speaker } & $\begin{array}{l}\text { Mixed } \\
\text { Mutation }\end{array}$ & $\begin{array}{l}\text { Ambiguous } \\
\text { Lenition }\end{array}$ & $\begin{array}{l}\text { Incorrect } \\
\text { Lenition }\end{array}$ & $\begin{array}{l}\text { No } \\
\text { Mutation }\end{array}$ & $\begin{array}{l}\text { Total } \\
\text { contexts }\end{array}$ \\
\hline \multirow{6}{*}{ Diwan } & A (8) & 0 & 2 & 1 & 7 & 10 \\
\hline & A (10) & 0 & 1 & 2 & 5 & 8 \\
\hline & B (13) & 4 & 0 & 2 & 7 & 13 \\
\hline & B (15) & 2 & 0 & 0 & 8 & 10 \\
\hline & T (14) & 2 & 3 & 2 & 7 & 14 \\
\hline & T (15) & 11 & 1 & 1 & 10 & 23 \\
\hline \multirow{7}{*}{ Divyezh } & AJ & 0 & 2 & 1 & 12 & 15 \\
\hline & BK & 0 & 5 & 14 & 17 & 36 \\
\hline & $\mathbf{C G}$ & 6 & 3 & 2 & 11 & 22 \\
\hline & EL & 0 & 1 & 0 & 30 & 31 \\
\hline & $\mathbf{F}$ & 2 & 2 & 2 & 3 & 9 \\
\hline & FM & 5 & 5 & 9 & 7 & 26 \\
\hline & $\mathbf{Y}$ & 0 & 3 & 5 & 1 & 9 \\
\hline
\end{tabular}

Table 4

Mutation usage: children. The children are divided by schooling type. The numbers in brackets following speakers A, B and T refer to their ages on each of the two fieldwork visits. 


\section{REFERENCES}

Awbery, Gwenllian M. 1986. Moves towards a simpler, binary mutation system in Welsh. In Henning Andersen (ed.) Sandhi Phenomena in the Languages of Europe, 161-166. Berlin; New York; Amsterdam: Mouton de Gruyter.

Ball, Martin J. 1993. Initial-consonant mutation in modern spoken Welsh. MultilinguaJournal of Cross-Cultural and Interlanguage Communication 12(2), 189-206.

Baxter, Robert Neal. 2009. New technologies and terminological pressure in lesser-used languages: the Breton Wikipedia; from terminology consumer to potential terminology provider. Language Problems and Language Planning 33(1), 60-80.

Bothorel, André. 1982. Etude phonétique et phonologique du breton parlé à Argol (Finistère-Sud). Lille: Atelier national réproduction des thèses, Université de Lille III.

Broudic, Fañch. 2009. Parler breton au XXIe siècle: Le nouveau sondage de TMORégions. Brest: Emgleo Breiz.

Broudic, Fañch. 2010. L'enseignement du et en breton: Rapport à Monsieur le Recteur de l'Académie de Rennes. Brest: Emgleo Breiz.

Cheveau, Loïc. 2006. Les mutations consonantiques en Breton Vannetais Littéraire et en Breton Lorientais. Journal of Celtic Linguistics 10, 1-15.

Costaouec, Denis. 1998. A propos des 'mutations consonantiques' du breton. La Linguistique 34(1), 87-106.

Costaouec, Denis. 2010. Contraintes et libertés en phonologie: neutralisations et faits d'assimilation en breton. La Bretagne Linguistique 15, 123-145.

Davalan, Nikolaz. 1999. Interférences linguistiques chez des enfants scolarisés en breton. Klask 5, 97-118. 
Denis, Pierre. 1977. Etude structurale d'un parler breton. Doctorat ès lettres, Université de Haute Bretagne.

Dorian, Nancy C. 1973. Grammatical Change in a Dying Dialect. Language 49(2), 413438.

Dorian, Nancy C. 1977. The problem of the semi-speaker in language death. International Journal of the Sociology of Language 12, 23-32.

Dresher, Elan \& Aditi Lahiri. 2005. Main stress left in Early Middle English. In Michael Fortescue, Eva Skafte Jensen, Jens Erik Mogensen \& Lene Schøsler (eds.) Historical Linguistics 2003: Selected papers from the 16th International Conference on Historical Linguistics, Copenhagen, 11-15 August 2003, 75-85. Amsterdam: John Benjamins Publishing Company.

Dressler, Wolfgang U. 1972. On the Phonology of Language Death. Proceedings of the Chicago Linguistics Society 8, 448-457.

Dressler, Wolfgang U. \& Josef Hufgard. 1980. Études phonologiques sur le breton sudbigouden. Wien: Verlag der Österreichischen Akademie der Wissenschaften.

Dressler, Wolfgang U. 1991. The sociolinguistic and patholinguistic attrition of Breton phonology, morphology and morphonology. In Herbert W. Seliger \& Robert Michael Vago (eds.) First Language Attrition, 99-112. Cambridge: Cambridge University Press.

Fagyal, Zsuzsanna, Douglas Kibbee \& Fred Jenkins. 2006. French: A Linguistic Introduction. Cambridge: Cambridge University Press.

Falc'hun, François. 1951. Le système consonantique du breton; avec une étude comparative de phonétique expérimentale. Rennes: Plihon. 
Falc'hun, François. 2005. Études sur la langue bretonne : système consonantique, mutations et accentuation. Ploudalmézeau: Éditions Label LN.

Favereau, Francis. 1984. Langue quotidienne, langue technique et langue littéraire dans le parler et la tradition orale de Poullaouen. Doctorat d'état, Université de Rennes II.

Favereau, Francis. 1997. Grammaire du breton contemporain. Morlaix: Skol Vreizh.

Gathercole, Virginia C. Mueller \& Enlli M. N. Thomas. 2005. Minority language survival: input factors influencing the acquisition of Welsh. In James Cohen, Kara T. McAlister, Kellie Rolstad \& Jeff MacSwan (eds.) ISB4 Proceedings of the 4th International Symposium on Bilingualism, 852-874. Somerville: Cascadilla Press.

Gathercole, Virginia C. Mueller \& Enlli M. N. Thomas. 2009. Bilingual first-language development: Dominant language takeover, threatened minority language take-up. Bilingualism: Language and Cognition 12(02), 213-237.

German, Gary. 2007. Language Shift, Diglossia and Dialectal Variation in Western Brittany: the Case of Southern Cornouaille. In Hildegard L. C. Tristram (ed.) The Celtic Languages in Contact: Papers from the Workshop within the Framework of the XIII International Congress of Celtic Studies, Bonn, 26-27 July 2007, 146-192. Potsdam: Potsdam University Press.

Hannahs, S. J. 2011. Celtic Mutations. In Marc van Oostendorp, Colin J. Ewen, Elizabeth Hume \& Keren Rice (eds.) The Blackwell Companion to Phonology, Volume V. 2807-2830. Oxford: Blackwell.

Hennessey, John S., Jr. 1990. Spirantization to lenition in Breton: Interpretation of morphophonological variability. In Martin J. Ball, James Fife, Erich Poppe \& Jenny Rowland (eds.) Ieithyddiaeth Geltaidd / Celtic Linguistics: readings in the 
Brythonic languages. Festschrift for T. Arywn Watkins, 209-224. Amsterdam; Philadelphia: John Benjamins.

Hornsby, Michael. 2005. Néo breton and questions of authenticity. Estudios de Sociolingüística 6(2), 191-218.

Jackson, Kenneth Hurlstone. 1967. A historical phonology of Breton. Dublin: Dublin Institute for Advanced Studies.

Jones, Mari C. 1998. Language Obsolescence and Revitalization: Linguistic Change in Two Sociolinguistically Contrasting Welsh Communities. Oxford: Clarendon Press.

Kennard, Holly J. 2014. The persistence of verb second in negative utterances in Breton. Journal of Historical Linguistics 4(1), 1-39.

Le Dû, Jean. 1986. A sandhi survey of the Breton language. In Henning Andersen (ed.) Sandhi Phenomena in the Languages of Europe, 435-450. Berlin; New York; Amsterdam: Mouton de Gruyter.

Le Roux, Pierre. 1924-1963. Atlas linguistique de la Basse Bretagne. Paris: Champion. Lisker, Leigh \& Arthur S. Abramson. 1964. A cross-language study of voicing in initial stops: Acoustical measurements. Word 20(3), 384-422.

Mikuteit, Simone \& Henning Reetz. 2007. Caught in the ACT: The Timing of Aspiration and Voicing in East Bengali. Language and Speech 50(2), 247-277.

Ofis Publik ar Brezhoneg. 2014. L'enseignement bilingue en 2013. Retrieved from http://www.fr.opab-oplb.org/47-enseignement.htm [Accessed: 19 March 2015]

Press, J. Ian. 1986. A Grammar of Modern Breton. Berlin: Mouton de Gruyter.

Press, J. Ian. 2009. Breton. In Martin J. Ball \& Nicole Müller (eds.) The Celtic Languages, 2nd edn. 427-487. London; New York: Routledge. 
Reetz, Henning \& Allard Jongman. 2009. Phonetics: transcription, production, acoustics, and perception. Oxford: Wiley-Blackwell.

Stephens, Janig. 1993. Breton. In Martin J. Ball \& James Fife (eds.) The Celtic Languages, 349-409. London: Routledge.

Ternes, Elmar. 1992. The Breton Language. In Donald MacAulay (ed.) The Celtic Languages, 371-452. Cambridge: Cambridge University Press.

Thomas, Enlli M. N. \& Virginia C. Mueller Gathercole. 2007. Children's productive command of grammatical gender and mutation in Welsh: an alternative to rulebased learning. First Language 27(3), 251-278.

Thomas, Enlli M. N. \& Robert Mayr. 2010. Children's Acquisition of Welsh in a Bilingual Setting: A Psycholinguistic Perspective. In Delyth Morris (ed.) Welsh in the Twenty-First Century, 99-117. Cardiff: University of Wales Press.

Timm, Lenora A. 1985. Breton Mutations: Literary vs. vernacular usages. Word 35, 95107.

Wmffre, Iwan. 1998. Central Breton. Unterschliessheim: Lincom Europa.

Author's address: Faculty of Linguistics, Philology \& Phonetics, University of Oxford, Clarendon Press Centre, Walton Street, Oxford, OX12HG UK holly.kennard@ling-phil.ox.ac.uk 


\title{
FOOTNOTES
}

\begin{abstract}
${ }^{1}$ We would like to thank Loïc Cheveau and two anonymous reviewers for their detailed and invaluable comments on previous versions of this article. Earlier analyses of data were presented at the XIVth International Congress of Celtic Studies (Maynooth, 2011) and at New Speakers in a Multilingual Europe (Barcelona, 2014), and we are very grateful to the participants for their feedback. We would also like to thank Henning Reetz and Adam Roberts for their help with the statistics in this paper. This work was supported by the European Research Council (Grant FP7-IST-269670; PI Lahiri), and the fieldwork was funded by Jesus College, Oxford.
\end{abstract}

The abbreviations in glosses follow the Leipzig Glossing Rules. Additional abbreviations are as follows: $\mathrm{PRT}=$ particle, $\mathrm{SIT}=$ situational, $\mathrm{VN}=$ verbal noun .

${ }^{2}$ The uvular rhotic may be a trill $[\mathrm{R}]$, but may equally be a fricative $[\mathrm{B}]$, as is common in many varieties of French.

${ }^{3}$ As mentioned above, there is a lot of dialectal variation in the realisation of these phonemes, lenition of $/ \mathrm{g} /$ being a particular example. In the written language, this takes the form $c^{\prime} h$, a grapheme which generally represents the fricative $[\mathrm{x}]$. However, when it is the result of lenition of $g$, most writers agree that it is or may be realised as [h], as in Table 1. Jackson (1967) writes that while the grapheme $c$ 'h has been in use since the seventeenth century, it seems to mean different things in different dialects, and even in literary Breton, it may be realised as [x], [h] or [h]. Falc'hun (2005: 222) makes it clear that within a particular dialect, different contexts result in different realisations of the consonant. Actual usage varies even more, with $c^{\prime} h$ being realised as $[\mathrm{b}]$ or $[\mathrm{\gamma}]$ in some dialects (see, e.g. Cheveau 2006), or even deleted entirely, in a manner akin to Welsh (where $g$ is deleted when lenited). 
${ }^{4}$ Lenition is not the main focus of this study, and so these instances form only a small fraction of the contexts in which lenition can be found. For a more detailed survey, see, for example, Press (1986).

${ }^{5}$ Some dialects also have provection of fricatives and even sonorants - for more details, see for example Wmffre's (1998) discussion of central Breton dialects.

${ }^{6}$ Several dialects have lenition after $m a$ : see Favereau (1997: 162).

${ }^{7}$ The uninflected form zo would normally be expected here (cf. example (18a)), as it is the form of the verb bezañ 'to be' used after an initial subject or direct object. The conjugated situational form emañ would normally only be used sentence-initially, or following an element other than the subject or direct object. The children often confuse the various forms of bezañ, in much the same way as Davalan (1999) reports.

${ }^{8}$ Falc'hun (1951) gives these measurements in centiseconds.

9 'These two consonants are differentiated by the fact that [d] is expressed, at the lower end of the spectrum, by a "voicing band", indicating its voiced character, while $[\mathrm{t}]$ is realised voiceless.' 